\title{
IMPACTS OF THE AFFORDABLE CARE ACT DEPENDENT COVERAGE PROVISION ON HEALTH-RELATED OUTCOMES OF YOUNG ADULTS
}

\author{
Silvia Barbaresco \\ Charles J. Courtemanche \\ Yanling Qi \\ Working Paper 20148 \\ http://www.nber.org/papers/w20148 \\ NATIONAL BUREAU OF ECONOMIC RESEARCH \\ 1050 Massachusetts Avenue \\ Cambridge, MA 02138 \\ May 2014
}

We thank Yaa Akosa Antwi, Kitt Carpenter, Jim Marton, Melinda Pitts, Anne Royalty, Chris Ruhm, Kosali Simon, Erdal Tekin, and audiences at the American Society of Health Economists Biennial Conference, University of Virginia, and Vanderbilt University for valuable comments. The views expressed herein are those of the authors and do not necessarily reflect the views of the National Bureau of Economic Research.

NBER working papers are circulated for discussion and comment purposes. They have not been peerreviewed or been subject to the review by the NBER Board of Directors that accompanies official NBER publications.

(C) 2014 by Silvia Barbaresco, Charles J. Courtemanche, and Yanling Qi. All rights reserved. Short sections of text, not to exceed two paragraphs, may be quoted without explicit permission provided that full credit, including (C) notice, is given to the source. 
Impacts of the Affordable Care Act Dependent Coverage Provision on Health-Related Outcomes

of Young Adults

Silvia Barbaresco, Charles J. Courtemanche, and Yanling Qi

NBER Working Paper No. 20148

May 2014, Revised January 2015

JEL No. I12,I13,I18

\section{ABSTRACT}

The first major insurance expansion of the Affordable Care Act - a provision requiring insurers to allow dependents to remain on parents' health insurance until turning 26 - took effect in September 2010. We estimate this mandate's impacts on numerous outcomes related to health care access, preventive care utilization, risky behaviors, and self-assessed health. We estimate difference-in-differences models with 23-25 year olds as the treatment group and 27-29 year olds as the control group. For the full sample, the dependent coverage provision increased the probabilities of having health insurance, a primary care doctor, and excellent self-assessed health, while reducing body mass index. However, the mandate also increased risky drinking and did not lead to any significant increases in preventive care utilization. Subsample analyses reveal particularly large gains for men and college graduates.

Silvia Barbaresco

Georgia State University

Box 3992

Atlanta, GA 30302

sbarbaresco1@student.gsu.edu

Charles J. Courtemanche

Georgia State University

Andrew Young School of Policy Studies

Department of Economics

P.O. Box 3992

Atlanta, GA 30302-3992

and NBER

ccourtemanche@gsu.edu
Yanling Qi

Georgia State University

Andrew Young School of Policy Studies

Department of Economics

Atlanta, GA 30302

yqi3@gsu.edu 


\section{Introduction}

The Patient Protection and Affordable Care Act (ACA) of March 2010 aimed to achieve nearly universal coverage in the United States through a combination of mandates, subsidies, Medicaid expansions, and health insurance exchanges (Gruber, 2011). Although the majority of the ACA's provisions just took effect in 2014, one important component of the law - a dependent coverage provision - was implemented on September $23^{\text {rd }}$, 2010. This provision allows dependents to remain on a parent's private health insurance plan until the start of the first plan year after they turn 26 years old. Previously, private insurers often dropped non-student dependents at age 19 and student dependents at age 23 (Anderson et al., 2012 and 2014).

Many states already had some form of dependent coverage mandate before the ACA, but the state laws are typically weaker. Most state laws have an age threshold below 26 or require additional criteria, such as being a full-time student, living with one's parents, or not being married. Moreover, state laws do not apply to self-funded benefit programs, and more than half of private sector workers with employer-provided health insurance are in self-funded plans (Monheit et al., 2011). Perhaps because of these limitations, Monheit et al. (2011) and Levine et al. (2011) find that state dependent coverage mandates only lead to small increases in dependent coverage that are offset by a decline in young adults holding their own policies. In contrast, the ACA provision applies to all young adults under age 26 and all private plans. It therefore has the potential to dramatically affect young adults across the country, including in states with a preexisting dependent coverage provision.

The ACA dependent coverage expansion provides a unique opportunity to study the impacts of a health insurance intervention specific to young adults, the age group with the highest uninsured rate (Levine et al., 2011). Prior to the ACA, the uninsured rate was 29\% 
among individuals ages $18-24$ and $27 \%$ among those $25-34$, compared to $19 \%$ for $35-44$ year olds and 14\% for 45-64 year olds (DeNavas-Walt et al., 2010). Since any attempt to obtain universal coverage necessarily involves large coverage expansions among young adults, it is important to understand the effects of insurance on this group. It is unclear the extent to which results from other contexts - such as Medicaid, Medicare, or the Massachusetts health care reform of 2006 - are applicable. Young adults are generally healthier than the populations covered by these programs, and therefore may experience smaller gains from health insurance. Alternatively, young adults may be relatively poor and therefore respond strongly to reduced outof-pocket costs of medical care. ${ }^{1}$

Given the short amount of time since its implementation, researchers are only beginning to study the impacts of the ACA dependent coverage provision. Cantor et al. (2012) and Sommers and Kronick (2012) show that the mandate increased health insurance coverage for young adults across all racial groups and regardless of employment status. Sommers et al. (2013) find that the provision increased insurance coverage among young adults, while reducing delays in getting care and care foregone because of cost. Akosa Antwi et al. (2013) again find an increase in insurance coverage, but they also present evidence of labor market consequences such as young adults shifting from full-time to part-time jobs. Akosa Antwi et al. (2014) show that the mandate increased young adults' utilization of inpatient care, particularly for mental illness. Chua and Sommers (2014) do not find any evidence that the provision affected health care use, but they do find a reduction in out-of-pocket medical expenses and increases in excellent self-reported physical and mental health.

\footnotetext{
${ }^{1}$ Aside from age, the ACA dependent coverage mandate is also a unique coverage expansion in that it represents an expansion of private rather than public insurance, and that, since it only affects those whose parents have insurance, the treated population may be of higher socioeconomic status than that of other interventions.
} 
These papers all share a common general research design: comparing changes in outcomes among the treated age range 19-25 to those of other young adults. The age range used for the control group varies across these studies, with some including individuals up to 34 years old (Sommers and Kronick, 2012; Sommers et al., 2013; Chua and Sommers, 2014). Slusky (2013) questions the validity of this approach, arguing that different age groups are often subject to different economic shocks. He runs placebo tests using data from before the mandate and artificial "treatment" dates, finding that the same specification estimates significant "effects" more often than could be attributed to chance. He suggests narrowing the age bandwidths of the treatment and control groups as a possible solution.

We contribute to this literature on the ACA dependent coverage provision in four ways. First, we consider a number of new outcomes. Using data from the Behavioral Risk Factor Surveillance System (BRFSS), we investigate 18 outcomes related to health care access, utilization of preventive care, risky health behaviors, and self-assessed health. The health care access measures include having insurance, a primary care doctor, and any foregone care because of cost. Our preventive care measures are dummies for recent flu vaccinations, well-patient checkups, and pap tests. The health behavior outcomes reflect smoking, drinking, body mass index, exercise, and pregnancy. The self-assessed health variables relate to overall, mental, and physical health as well as health-related functional limitations. Of these outcomes, only insurance coverage, foregone care because of cost, and self-assessed physical and mental health are studied in other papers in the literature. To our knowledge we are the first to investigate the ACA dependent coverage provision's impact on preventive care or health behaviors. Moreover, although Chua and Sommers (2014) examine self-assessed physical and mental health, their measures and ours are meaningfully different. They use dummies for self-reporting excellent 
physical and mental health, so their estimates only capture changes at the upper end of the health distribution. In contrast, we utilize five measures that should together capture changes at various parts of the distribution. A dummy for excellent overall health reflects the high end, a dummy for very good or excellent health reflects a somewhat lower portion, and three more severe outcomes - number of days of the past 30 not in good physical health, not in good mental health, and with health-related limitations - reflect an even lower portion. This distinction will prove critical to the results.

Our second contribution is to push further than prior studies toward addressing the methodological concerns raised by Slusky (2013), both by using narrow age ranges for the treatment and control groups and by validating these selections through placebo testing. Our treatment group consists of individuals ages 23-25, slightly below the dependent coverage provision's age cutoff, and our control group consists of those slightly above the cutoff at ages 27-29. We run placebo tests checking for "effects" of artificial interventions in the pre-treatment period. Our classifications perform well in the placebo tests, whereas the wider age ranges commonly used in the literature prove more problematic.

Another contribution is that we use over three full years of post-treatment data (2011 through 2013, plus a few months after implementation at the end of 2010). To our knowledge, none of the prior papers in the ACA dependent coverage provision literature have used more than one full year of post-treatment data, which leaves the estimates susceptible to confounding from temporary age-specific shocks and fluctuations. If estimated effects persist with three years of post-treatment data, we can be more confident that they are not driven by transitory movements in unobserved characteristics. 
Finally, we contribute to the literature by testing for heterogeneous effects. Of the outcomes included in our paper, heterogeneity in the effects of the ACA dependent coverage provision has only previously been evaluated for insurance coverage (Akosa Antwi et al., 2013; Sommers et al., 2013) and cost being a barrier to care (Sommers et al., 2013). We will find important heterogeneous effects on other outcomes as well, such as self-assessed health. Moreover, although Akosa Antwi et al. (2013) and Sommers et al. (2013) evaluate whether effects differ by certain demographic characteristics, neither paper tests for heterogeneous effects by socioeconomic status. ${ }^{2}$ We will find that the effects of the dependent coverage provision vary considerably by education level.

Our difference-in-differences results from the full sample suggest that the ACA dependent coverage provision improved health care access for young adults, had little effect on preventive care use, had mixed effects on risky health behaviors, and improved self-assessed health at the high end of the distribution. Specifically, we document improvements in four of the eighteen outcomes: health insurance coverage, access to a primary care doctor, excellent selfassessed health, and body mass index. However, we find evidence of an increase in risky drinking, and no clear effects in either direction on the remaining thirteen outcomes.

We evaluate heterogeneity in the effects of the mandate through subsample analyses, finding the greatest improvements in outcomes for men and college graduates. The increase in health insurance coverage was greater for men than women, and only men experienced statistically significant gains in any outcomes beyond health insurance: primary care access, exercise, and overall self-assessed health. Stratifying by education reveals that the insurance

\footnotetext{
${ }^{2}$ Sommers et al. (2013) note that testing for heterogeneity by educational attainment is difficult because many individuals in their treatment group - 19 to 25 year olds - are still in the process of completing their education. Another advantage of using a narrow age range for the treatment group - 23 to 25 year olds - is that excluding the prime college ages largely ameliorates this concern.
} 
expansions were similar for college graduates and non-college graduates. However, only college graduates experienced significant gains in any other outcomes besides insurance - specifically, primary care access, cost being a barrier to care, body mass index (BMI), obesity, and overall self-assessed health. Young adults with different education levels therefore appear to respond differently to exogenously obtaining health insurance.

\section{Health Insurance and Health-Related Outcomes}

The most obvious theoretical implication of health insurance is that by lowering the effective price of health care, health insurance should increase its utilization. However, increased health care utilization does not necessarily improve health. Diminishing marginal returns suggest that health care can only improve health up to a certain level (e.g. Grossman, 1972). Whether the additional consumption of medical care induced by insurance generates substantial gains in health therefore depends on the initial level of health capital. Since the uninsured can often obtain essential needs by paying directly or receiving charity care, these individuals need not have low baseline levels of health. Moreover, the marginal returns to health care differ for different outcomes. Risky health behaviors such as smoking, excessive drinking, and overeating might be particularly difficult to improve through health care, as they require lifestyle changes. Medical professionals' ability to influence health behaviors is generally limited to providing accountability, information, strategies, and sometimes drugs to make behavioral changes easier.

Another relevant issue when evaluating the impact of health insurance on health is that obtaining insurance could induce individuals to take more health risks, since the provision of health insurance decreases the financial losses associated with sickness. This concept is known as ex ante moral hazard (Ehrlick and Becker, 1972). Theoretically, ex ante moral hazard could both increase risky behaviors and reduce investments in preventive care. 
Finally, exogenous provision of health insurance could lead to income effects for individuals who used to purchase their own insurance policy but now are able to receive free or subsidized coverage, or for the newly-insured if their out-of-pocket medical expenses drop. The available evidence from natural experiments suggests that additional income increases health care utilization (Acemoglu et al., 2013), either increases BMI or has no effect (Lindahl, 2005; Schmeiser, 2009; Cawley et al., 2010), increases smoking along the intensive but not extensive margin (Apouey and Clark, 2014), and increases drinking (Apouey and Clark, 2014). The income effect may therefore improve health via medical care but worsen health via risky behaviors. Accordingly, evidence of income's causal effect on overall health is mixed, with Lindahl (2005) and Frijters et al. (2005) finding that it improves self-assessed health, Apouey and Clark (2014) finding that it improves mental health but not overall health, and Snyder and Evans (2006) showing that it raises mortality risk among seniors.

In sum, the effects of insurance on preventive health care utilization, risky health behaviors, and overall health status are theoretically ambiguous. Insurance may improve these outcomes through direct price effects, worsen them through ex ante moral hazard, or affect them in either direction through income effects. The net effects could differ for different outcomes. For instance, direct price effects might dominate for primary care utilization but moral hazard might dominate for risky behaviors. Empirical analysis is necessary to resolve this ambiguity.

Causally interpretable evidence generally confirms the prediction that insurance increases health care utilization for U.S. adults. Manning et al. (1987) analyzed the randomized RAND Health Insurance Experiment, finding that lower copayments increased doctor visits. Medicaid and Medicare expansions have been shown to increase utilization of primary and hospital care (Currie and Gruber, 1996a; Finkelstein et al., 2012; Taubman et al., 2014; Lichtenberg, 2002; 
Card et al., 2008). Other evidence suggests that the Massachusetts universal coverage initiative of 2006 increased preventive services while reducing emergency room utilization, avoidable hospitalizations, and medical needs unmet because of cost (Miller, 2011; Kolstad and Kowalski, 2012; Miller, 2012; Van der Wees et al., 2013). More directly relevant to our study population, Anderson et al. (2012 and 2014) exploit the sharp drops in coverage on parents' insurance at ages 19 and 23 to show that losing coverage reduced young adults' emergency room and hospital visits. Finally, as mentioned previously, Akosa Antwi et al. (2014) show that the ACA dependent coverage provision increased hospital admissions, although Chua and Sommers (2014) find no significant effects on survey measures of hospital, primary care, or prescription drug utilization.

The evidence of health insurance's effect on health is mixed. The RAND experiment only found that better insurance coverage improved health for certain subgroups (Brook et al., 1983). Medicaid expansions increase self-reported overall, physical, and mental health and reduce mortality, but have no statistically detectable effects on laboratory-measured health outcomes (Currie and Gruber, 1996b; Finkelstein et al., 2012; Sommers et al., 2012; Baicker et al., 2013). Card et al. (2009) find a reduction in the mortality rate among recently hospitalized Medicare recipients, but Finkelstein and McKnight (2008) find no significant effect of Medicare on the mortality rate of seniors in general. Evidence suggests that the Massachusetts reform improved self-assessed overall, physical, and mental health, while decreasing functional limitations, joint disorders, and mortality (Van der Wees et al., 2013; Courtemanche and Zapata, 2014; Sommers et al., 2014). As mentioned previously, Chua and Sommers (2014) find that the ACA dependent provision increased the probabilities of self-reporting excellent physical and mental health.

Evidence on the causal effects of health insurance on risky health behaviors is also mixed. 
Brook et al. (1983) find no evidence that insurance affected smoking or body weight in the RAND experiment. Dave and Kaestner (2009) report that Medicare decreased physical activity while increasing smoking and drinking. Finkelstein et al. (2012) do not find any significant impacts of Medicaid on smoking or BMI. Courtemanche and Zapata (2014) find that the Massachusetts reform reduced body mass index and did not affect smoking or physical activity.

In sum, there is little prior evidence on the effects of health insurance on young adults' access to care, preventive care utilization, risky health behaviors, or health. Given the theoretical ambiguities and variation in empirical findings discussed above, we cannot assume prior results from other contexts such as Medicaid and Medicare generalize. For instance, young adults' relatively high baseline levels of health might lead them to have relatively inelastic demand for health care or a low marginal effect of health care on health. On the other hand, young adults' demand for health care could be relatively elastic given their generally low income and wealth levels. Moreover, one might expect young adults to be the most susceptible to ex ante moral hazard since this is often the life stage in which opportunities to engage in particular risky behaviors (e.g. binge drinking) are introduced.

\section{Data}

Our main data source is the BRFSS, a telephone survey conducted by state health departments in conjunction with the U.S. Centers for Disease Control and Prevention to collect information on health and health behaviors. The survey is conducted monthly through a random digit dialing method that selects a representative sample of respondents from the noninstitutionalized population of adults at least 18 years old. The BRFSS provides several advantages for our analyses. First, it contains a wide range of appropriate outcome variables. Second, it includes demographic characteristics as well as state, month, and year identifiers that 
allow us to construct the treatment variable and jointly control for many different factors. Next, it contains a much larger number of observations than other datasets with the necessary variables. Finally, the BRFSS includes a number of pre-treatment waves that allow for detailed testing of differential trends in the outcomes between treatment and control groups.

Our primary analysis sample consists of the 2007-2013 waves, which include the year the ACA dependent coverage mandate took effect plus three years on both sides. One reason we exclude the years before 2007 is to limit our sample to years of relatively poor economic performance. This reduces the possibility of confounding from differential impacts of macroeconomic shocks on the health-related outcomes of different age groups. However, robustness checks and placebo tests will utilize data as far back as 2001 . We do not use any waves before 2001 because the BRFSS made major changes to the survey in that year. Many of the questions used to construct our outcome variables are either not available in earlier years or differ in non-trivial ways.

Most of our analyses use ages 23-25 as the treatment group and ages 27-29 as the control group. Following much of the prior literature, 26 year olds are excluded because their treatment status is ambiguous: they may still be covered by the ACA mandate depending on their birthdate and the start date of their parents' insurance plan year (Akosa Antwi et al., 2013). Although the prior literature uses 19-25 as the treatment group, we prefer 23-25 for two reasons. ${ }^{3}$ First, prior to the ACA, insurers most commonly dropped non-student dependents from parents' plans at age 19, but most commonly dropped student dependents at age 23. Excluding 19-22 year olds therefore results in a "cleaner" treatment group, i.e. a higher proportion of the treatment group actually being affected by the treatment. Accordingly, Akosa Antwi et al. (2014) show that the

\footnotetext{
${ }^{3}$ Studies in the literature utilize somewhat different control groups. Cantor et al. (2012) use 27-30 year olds; Sommers and Kronick (2012), Sommers et al. (2013), and Chua and Sommers (2014) use 26-34 year olds; Akosa Antwi et al. (2013) use 16-18 and 27-29 year olds; and Akosa Antwi et al. (2014) use 27-29 year olds.
} 
ACA dependent coverage provision's impact on having insurance was more than twice as large for 23-25 year olds as for 19-22 year olds. Second, Slusky (2013) shows that the models from prior papers with ages 19-25 as the treatment group lead to poor placebo test results for insurance and labor market outcomes. He suggests narrowing the age bandwidth as a potential solution. Indeed, we will show that wider age ranges lead to problematic placebo test results for our outcomes as well, and that our narrower age range performs better.

We utilize eighteen different health-related dependent variables. The first three relate to health care access: dummy variables reflecting whether the respondent has any health insurance, has a primary care physician, and had any medical care needed but not obtained because of cost in the previous year. Unfortunately, the BRFSS does not include more detailed questions on health insurance, such as the source of coverage. The next three outcomes - dummies for having a flu vaccination (shot or spray), a well-patient doctor check-up visit (e.g. physical), and a pap test (for women) in the previous year - reflect preventive care utilization. ${ }^{4}$ The next category of variables relates to risky health behaviors: a dummy for whether the individual currently smokes, number of alcoholic drinks in the past 30 days, a dummy for being a risky drinker (more than 30 drinks total or at least one occasion with four or more drinks for women, more than 60 drinks total or at least one occasion with five or more drinks for men), ${ }^{5}$ body mass index (BMI=weight in $\mathrm{kg} /$ height in $\left.\mathrm{m}^{2}\right),{ }^{6}$ a dummy for obese (BMI $\geq 30$ ), a dummy for whether an unmarried female respondent is pregnant (the only proxy for risky sexual activity available in the BRFSS), and a

\footnotetext{
${ }^{4}$ Other preventive care variables typically studied in the literature, such as mammograms and prostate exams, are not relevant for our study population of young adults.

${ }^{5}$ The dummy for risky drinker is created to come as close as the BRFSS data will allow to the National Institute on Alcohol Abuse and Alcoholism's definition of at-risk drinking: more than 7 drinks per week total or at least one occasion with three or more drinks for women, and more than 14 drinks per week total or at least one occasion with four or more drinks for men. See http://pubs.niaaa.nih.gov/publications/womensfact/womensfact.htm.

${ }^{6}$ Body mass index is based on self-reported height and weight, which are prone to measurement error (Cawley, 2004). Researchers have repeatedly found that this measurement error does not affect the signs and significance of regression estimates with BMI as a dependent variable, though it may slightly attenuate the magnitude of the estimates (e.g. Lakdawalla et al., 2002; Courtemanche et al., 2014; Courtemanche et al., forthcoming).
} 
dummy for obtaining any recreational exercise in the past 30 days. ${ }^{7}$ Finally, we include several variables related to self-assessed health status: a dummy for whether overall health is very good or excellent, a dummy for whether overall health is excellent, and days of the last 30 not in good mental health, not in good physical health, and with health-related functional limitations. Although self-assessed health is subjective, research has repeatedly found it to be correlated with objective measures of health such as mortality (e.g. Idler and Benyamini, 1997; DeSalvo et al., 2006; Phillips, Der, and Carroll, 2010). Self-assessed health is also a global measure of health that captures the full range of possible diseases and limitations (Idler and Benyamini, 1997). ${ }^{8}$

We also utilize a wide array of control variables. These include dummy variables for each year of age, gender, race/ethnicity, marital status, education, household income category, number of children in the household, whether the respondent reports her primary occupation as student, and whether the respondent is unemployed. Additionally, we control for monthly state unemployment rate, obtained from the Bureau of Labor Statistics. As mentioned previously, we are concerned about different impacts of the recession on different age groups, so controlling for several variables related to economic conditions at both the individual and aggregate levels could potentially be important. We also control for whether the respondent's state had any dependent coverage mandate covering her age*marital status*student status group in the survey year based on information from the National Conference of State Legislatures (2010). ${ }^{9}$ Additionally, in the flu vaccination regressions we control for interactions of the age fixed effects with the number of positive influenza tests in the country during the particular flu season (a proxy for severity of the

\footnotetext{
${ }^{7}$ Unfortunately, the more detailed BRFSS questions on physical activity are only available in odd numbered survey years and changed dramatically in 2011, so they are not useful for our analyses.

${ }^{8}$ Moreover, other commonly-used measures of health are not practical in our context. Mortality rates are likely too low among young adults to estimate effects of coverage expansions with meaningful precision, while measures of avoidable hospitalizations confound insurance's impact on health with the reduction in effective prices.

${ }^{9}$ Note that not everyone coded as a 1 for state mandate is actually "treated" by such a mandate. Additional qualifiers beyond age, student status, and marital status exist in some states, while young adults whose parents' employers self-insure are also not covered by state mandates.
} 
flu season). Flu seasons in the post-treatment years were much more severe than those in the pretreatment years, so adding these interactions prevents the estimates from being confounded by differential responses to flu season severity by young adults of different ages. ${ }^{10}$

Finally, we include a dummy for whether the respondent is part of a "cell phone only" component of the sample, added in 2011 (this variable is 0 for all respondents before 2011). The fact that individuals who only used cell phones were not explicitly included in the sample until 2011 raises the question of whether our sample makeup meaningfully changed at about the same time the post-treatment period began. To address this issue, we not only control for "cell phone only" users but also utilize the BRFSS sampling weights in all analyses. We found that these weights eliminate any sharp changes in sample demographic characteristics in 2011. Additionally, this issue would only bias our regression estimates if the relationship between the outcomes of landline and cell phone users is different among 23-25 year olds than among 27-29 year olds, and in a way that is not captured by the controls. It is not obvious why this would be the case. Accordingly, we have verified (results available upon request) that dropping individuals who only use cell phones from our sample has very little effect on the coefficient estimates, though it does generally increase the standard errors due to the reduced sample size.

After excluding observations with missing data for any of the control variables, Table 1 reports the sample sizes for the regressions for each dependent variable, along with the numbers of individuals in the treatment and control groups. The sample sizes differ slightly across dependent variables for two reasons. First, each health-related variable is missing for a different

\footnotetext{
${ }^{10}$ Specifically, for the pre-treatment years 2007,2008 , and 2009, there were $23,753,39,827$, and 27,682 positive influenza test results in the corresponding flu seasons 2006-2007, 2007-2008, and 2008-2009. For the post- or during-treatment years 2010, 2011, 2012, and 2013, there were 157,449, 55,403, 27,012, and 75,342 number of influenza test results in the corresponding flu seasons 2009-2010, 2010-2011, 2011-2012, and 2012-2013 (CDC, 2014). The large 2009-2010 flu season number largely reflects the swine flu pandemic, but two of the three subsequent seasons were still relatively strong. Our results suggest that younger young adults respond more strongly to flu season severity than older young adults; therefore, omitting these interactions would lead to biased estimates.
} 
number of respondents. Second, the health-related variables have different "reflection periods;" some apply to the present (e.g. current smoker), while others refer to a 30-day period (e.g. number of alcoholic drinks in the past 30 days) and others to a one-year period (e.g. any wellpatient doctor visit in the past year). We are concerned that short-run estimates would be misleading for variables with a long reflection period. ${ }^{11}$ We therefore drop respondents surveyed during this period of ambiguity; e.g. for well-patient doctor visit in the past year we drop October 2010 through September 2011, while for drinks in the past 30 days we drop only October 2010. ${ }^{12}$

Table 2 lists the control variables and compares the pre-treatment (January 2007 through September 2010) summary statistics of the treatment and control groups. Individuals in the treatment group are less likely to be married, have a college degree, earn a high income, and have children in the household, and they are more likely to be students or employed.

Table 3 reports the pre- and post-treatment sample means of the outcome variables for the treatment and control groups, and calculates the simple difference-in-difference of means. Prior to the ACA dependent coverage provision, the uninsured rate was higher for young adults in the treatment group than those in the control group. The treatment group had lower rates of health care utilization and health care access than the control group; higher drinking and unmarried pregnancy rates but healthier levels of risky drinking, BMI, obesity, and exercise; and broadly similar levels of smoking and self-assessed health. Comparing changes in the post- and pretreatment means for the treatment and control groups, the difference-in-differences are positive and significant for any insurance, primary care doctor, excellent health, and risky drinker;

\footnotetext{
${ }^{11}$ For example, suppose a respondent is surveyed in November 2010, the second month of the post-implementation period. The respondent would be classified as post-treatment, but her answer about well-patient doctor visits in the past year would reflect only two months of the post-treatment period and ten months of the pre-treatment period.

${ }^{12}$ For flu vaccinations in the past year, we only drop October 2010 through December 2010, as opposed to dropping a full year. We feel a shorter reflection period is appropriate in this case because flu vaccinations are typically administered in the fall. For instance, if someone surveyed in March 2011 reports being vaccinated in the past year, that vaccine almost certainly occurred during the post-treatment period (October 2010 or later).
} 
negative and significant for body mass index and obesity; and insignificant for the other outcomes - including all those in the preventive care category.

Simple difference-in-differences estimates account for fixed differences in unobservable characteristics between the treatment and control group, but are still susceptible to bias from time-varying observables and unobservables. Figures 1-3 show that at a first glance the pre-ACA trends for the treatment and control groups appear generally similar for most outcomes, providing preliminary evidence that changes over time in observables and unobservables may not be substantially different for 23-25 year olds and 27-29 year olds. We next turn to regression analyses that adjust for changes in observables. Later, we will also conduct more formal tests of the assumption of common trends in unobservables.

\section{Average Effects of the ACA Dependent Coverage Mandate Baseline Model}

We estimate the effects of the ACA dependent coverage provision on the eighteen healthrelated outcomes using reduced-form difference-in-differences regressions. While it is tempting to estimate instrumental variables models using the mandate as an instrument for having insurance coverage, we are not confident that the exclusion restriction would hold in such models because there are several other mechanisms through which the mandate could affect health-related outcomes besides the extensive margin of health insurance coverage. Other possible mechanisms include the intensive margin of coverage (switching from high deductible catastrophic coverage to more comprehensive coverage), income effects, and peer effects.

Our baseline regression is of the form

$$
Y_{i g s t}=\beta_{0}+\beta_{1}\left(\text { Treat }_{g} * \text { Post }_{t}\right)+\boldsymbol{\beta}_{2} \boldsymbol{X}_{\text {igst }}^{\prime}+\alpha_{g}+\varphi_{t}+\sigma_{s}+\varepsilon_{i g s t}
$$


where $Y_{i g s t}$ is the health-related outcome for individual $i$ of age $g$ living in state $s$ in time $t$, expressed in a month/year combination. ${ }^{13}$ Treat $_{g}$ is a dummy variable for whether age $g$ is in the treated age range 23-25 as opposed to the control age range 27-29. Post $_{t}$ indicates whether period $t$ is after the implementation of the provision (October 2010 or later). $\beta_{1}$ is the differencein-differences coefficient and it captures the difference between the effects of the mandate on the treatment and control groups. $\boldsymbol{X}_{\boldsymbol{i g s t}}^{\prime}$ is a vector of the aforementioned control variables for sex, race, marital status, education, income, children, cell phone survey, student status, individual and state unemployment, and state dependent coverage mandate. We also include fixed effects for each year of age, month/year of time (e.g. January of 2007), and state, denoted by $\alpha_{g}, \varphi_{t}$, and $\sigma_{s}$, respectively. $\varepsilon_{\text {igst }}$ is the error term. ${ }^{14}$ We do not separately include Treat $_{g}$ and Post $_{t}$ in the model because Treat $_{g}$ is perfectly collinear with the age fixed effects while Post $_{t}$ is perfectly collinear with the month/year fixed effects.

We report heteroskedasticity-robust standard errors clustered at the level of treatment: age. Following convention when there are a small number of clusters (six in our case), for hypothesis testing we use a $t$-distribution with degrees of freedom equal to the number of clusters minus one. The critical values used in our hypothesis tests are therefore considerably more stringent than those using the standard normal distribution. It is possible that even using stringent critical values might not be sufficient to eliminate the tendency to over-reject when the number of clusters is small (Cameron et al., 2008). However, the placebo tests in the next section will reject the null hypothesis even fewer than the expected number of times, suggesting that our

\footnotetext{
${ }^{13}$ Even though most of our outcomes are binary or non-negative count, we estimate linear models because they typically give reliable estimates of average effects (Angrist and Pischke, 2008). In unreported regressions (available upon request), we verify that the average treatment effects are very similar using probit regressions for the binary outcomes and negative binomial regressions for the count outcomes.

${ }^{14}$ In unreported regressions (available upon request) we have verified the results remain virtually identical if we replace the state fixed effects with fixed effects for each state-by-year combination.
} 
hypothesis tests are sufficiently conservative. One of our robustness checks will also address this issue.

The key identifying assumption in a difference-in-differences model is common counterfactual trends between the treatment and control groups; i.e. in the absence of the intervention the treatment and control groups would have experienced the same changes in outcomes. Slusky (2013) argues that this assumption is problematic when studying the impact of the ACA dependent coverage provision on labor market-related outcomes (e.g. sources of health insurance coverage, employment status, and work hours) since cyclical fluctuations in the economy have different effects on different age groups. Since economic fluctuations are related to health, ${ }^{15}$ Slusky's concern could also apply to health-related outcomes. As discussed previously, this is one of our main reasons for using narrow age bandwidths of 23-25 and 27-29.

\section{Robustness Checks}

We also estimate several variations of (1) as robustness checks. First, we run regressions including only the demographic controls (the sex, age, race, children, and marital status dummies) and fixed effects, excluding the economic controls since they may be endogenous to the dependent coverage provision. Obtaining access to parents' insurance could potentially influence a young adult's decisions about employment and education, which would then affect income. Including covariates related to employment, education, and income might therefore "control away" part of the causal effect of the policy.

Our next several robustness checks vary the time period included in the sample. In order to verify that the results are not driven by our chosen length of the pre-treatment period, we consider two alternatives: starting the sample in 2004 and 2001. Additionally, we run regressions

\footnotetext{
${ }^{15}$ Research generally shows that recessions are associated with improvements in health and health behaviors (e.g. Ruhm, 2000, 2002, 2005), although recent evidence suggests that the countercyclical nature of health observed in prior recessions may not have been present during our sample period (Ruhm, 2013; Tekin et al., 2013).
} 
dropping March 2010 through December 2010, as these months are somewhat ambiguous with respect to their treatment status. We drop March-September because the ACA was passed in March, so some insurance plans may have complied preemptively prior to the dependent coverage provision's official implementation in September. We drop October-December because, even though the mandate was implemented in September, insurers did not have to comply until the start of the next plan year, which is often January. ${ }^{16}$

Our final robustness check addresses the potential concern that standard errors may be understated because of autocorrelation given the small number of clusters. We collapse the data into one observation for each year of age in the pre-treatment period and one observation for each year of age in the post-treatment period, for a total of twelve observations. We then estimate

$$
\bar{Y}_{g t}=\gamma_{0}+\gamma_{1}\left(\text { Treat }_{g} * \text { Post }_{t}\right)+\gamma_{2} \text { Treat }_{g}+\gamma_{3} \text { Post }_{t}+\gamma_{4} \bar{X}_{g t}+\varepsilon_{g t}
$$

where the lines above variables indicate averages across all individuals of age $g$ in time period (pre- or post-treatment) $t$, weighted by the individual BRFSS sampling weights. Since the small sample size prevents all the control variables from being separately included, $\bar{X}$ is a single variable that summarizes the influence of all the controls. $\bar{X}$ is computed by regressing outcome $Y$ on the controls using the individual-level pre-treatment data, then predicting $Y$ for the whole sample based on the coefficient estimates, then aggregating in the same manner described above.

\section{$\underline{\text { Results }}$}

Table 4 presents the results for the baseline model and robustness checks. In addition to reporting estimated treatment effects and standard errors, for the baseline regressions we also report (in brackets) the treatment effects expressed in standard deviations of the dependent variables to provide some comparability of effect sizes across the different outcomes.

\footnotetext{
${ }^{16}$ Akosa Antwi et al. (2013) include two treatment variables to separately model the effects of the mandate during the implementation period and after full implementation. We have considered this specification in unreported regressions and the estimated post-implementation effects remain very similar.
} 
The results suggest sizeable improvements in health care access along at least some dimensions. We estimate that the ACA dependent coverage provision statistically significantly increased the insurance coverage rate of 23-25 year olds by between 5.5-6.7 percentage points, depending on the model. This is somewhat larger than the around 3-5 percentage point increase estimated by previous studies that use the broader treated age range of 19-25 (Cantor et al., 2012; Sommers and Kronick, 2012; Akosa Antwi et al., 2013; Sommers et al., 2013). ${ }^{17}$ Additionally, the mandate increased the probability of having a primary care doctor by 2.0-3.4 percentage points and decreased the probability of having any care needed but foregone because of cost by 1.6-2.3 percentage points. The effect on primary care doctor access is statistically significant in all specifications, but the effect on care foregone because of cost is never significant.

Despite this improved access, we do not find any evidence of increased preventive care utilization. We estimate a total of eighteen models across the three preventive care measures, and none of these models reveal a statistically significant positive effect of the dependent coverage provision. The estimated effects on flu vaccinations and pap tests are negative in most specifications and occasionally statistically significant. The estimates for well-patient checkup are all positive but never significant.

We find mixed evidence regarding the dependent coverage provision's impacts on risky health behaviors. No significant estimates are observed for smoking, pregnancy, or alcoholic drinks per month. However, the mandate statistically significantly increased the probability of risky drinking (excessive drinks per month or any binge drinking) in all specifications, with magnitudes ranging from 0.8-1.4 percentage points. The dependent coverage expansion therefore

\footnotetext{
${ }^{17}$ This discrepancy is consistent with Akosa Antwi et al.'s (2014) finding that the mandate's impact on the probability of having any coverage was around twice as large for 23-25 year olds than 19-22 year olds (4 compared to 2 percentage points). Alternatively, estimates using the treated age range 19-25 could be biased downward given the problems documented in our placebo tests and those of Slusky (2013).
} 
appears to affect drinking at only the high end of the distribution, which is consistent with an $e x$ ante moral hazard explanation since mild to moderate drinking generally does not increase the need for medical services. In contrast, the dependent coverage provision appears to improve weight-related behaviors. The mandate reduces BMI in all six specifications, with magnitudes ranging from -0.098 to -0.175 . All but one of the six estimates for BMI are significant, with the remaining one being nearly significant. The effect on obesity is also negative in all six models, though it is only significant in three. The effect on probability of having any exercise is positive in all specifications but only significant in one. It is possible that our inability to measure exercise in greater detail - e.g. calories burned per day from physical activity - prevents the emergence of further significant results. It is also possible that the reduction in BMI is coming via reduced caloric intake, which we are unable to measure in the BRFSS.

It is theoretically conceivable that insurance coverage could increase risky drinking but reduce weight. Health care access may be more helpful for losing weight than reducing drinking. Gains in information and accountability may both be greater for weight control than drinking: dieting strategies can be complicated and benefit greatly from professional advice, and accountability is greater for weight since patients are weighed at each visit. Additionally, the $e x$ ante moral hazard effect could be stronger for risky drinking than weight-related behaviors. Binge drinking has a non-trivial chance of resulting in immediate medical needs, either from alcohol poisoning, drunk driving accidents, or other injuries. ${ }^{18}$ In contrast, expenditures to treat diseases associated with obesity typically occur years down the road. Perhaps uninsured young adults assume that they will be insured by time these downside risks are realized, in which case ex ante moral hazard would not apply. In short, the direct price effect could dominate for BMI,

\footnotetext{
${ }^{18}$ In the US, approximately 80,000 cases of alcohol poisoning and 10,322 alcohol-impaired driving crashes occur annually, with these incidents disproportionately involving young adults (CDC, 2012; NHTSA, 2014). 599,000 alcohol-related injuries occur annually among 18-24 year old college students (NIAAA, 2013).
} 
while the ex ante moral hazard effect could dominate for drinking. Income effects may play a role as well, especially for alcohol consumption given the aforementioned evidence of a positive causal effect of income on drinking (Apouey and Clark, 2014).

Turning to the self-assessed health outcomes, the mandate increased the probability of young adults reporting excellent overall health by 1.3-1.5 percentage points and very good/excellent health by 1.1-1.8 percentage points. However, only the estimates for excellent health are significant, as the standard errors for very good/excellent health are larger. We do not find any evidence of effects on the variables representing more severe health problems: days not in good mental health, not in good physical health, and with health-related functional limitations. The lack of effects on our mental and physical health outcomes is particularly interesting in light of Chua and Sommers' (2014) finding that the ACA dependent coverage provision increased the probabilities of reporting excellent mental and physical health. Chua and Sommers' mental and physical health variables emphasize changes at the high end of the health distribution and may therefore correspond more closely to our variable for excellent overall health than our physical and mental health variables, which focus on "not good" health. In other words, both our results and those of Chua and Sommers are consistent with the provision's effects on mental and physical health being concentrated in the high end of the health distribution.

Finally, we provide a brief discussion of the relative magnitudes of the effects on different outcomes by comparing the treatment effects expressed in standard deviations of the dependent variables. Not surprisingly, the largest effect of 0.13 standard deviations is on the probability of having any health insurance coverage. The next largest statistically significant effect is on primary care doctor access ( 0.065 standard deviations), then excellent health $(0.032$ standard deviations), then risky drinker (0.026 standard deviations), then finally BMI (-0.017 
standard deviations). The largest statistically insignificant effects are on flu vaccinations (-0.033 standard deviations) and very good/excellent health (0.031 standard deviations).

\section{Placebo Tests}

We next provide a series of placebo tests to evaluate whether the previous results can credibly be interpreted as causal effects of the ACA dependent coverage provision. Following Slusky (2013), we estimate variants of equation (1) that test for "effects" of artificially-timed "treatments" during pre-treatment years. We estimate models for three different seven-year windows of pre-treatment data (to match the seven years used in our main 2007-2013 analyses): 2003-2009, 2002-2008, and 2001-2007. Since the first month after the implementation of the actual dependent coverage mandate was the $46^{\text {th }}$ month (October 2010) of our 2007-2013 sample, in each placebo test sample we date the implementation of the artificial intervention to the $46^{\text {th }}$ month (e.g. October 2006 for the 2003-2009 sample). We estimate (1) for each of the eighteen dependent variables in each of the three placebo test samples.

Table 5 reports the coefficient estimates of interest from these placebo tests. We run three tests for each of the eighteen dependent variables, though a test is not possible for checkups using 2001-2007 data since the checkup question was not asked until 2005. This leaves a total of 53 regressions. Given the large number of estimates, we would expect some significant results even for valid models. Specifically, approximately $0-1$ estimates should be significant at the $1 \%$ level, about 2-3 at the 5\% level, and about 5 at the $10 \%$ level. We obtain numbers even smaller than these. No estimated "treatment effects" are significant at the 1\% level, $2(3.8 \%)$ are significant at the 5\% level, and $3(5.7 \%)$ are significant at the $10 \%$ level. Moreover, we do not obtain more than one placebo test rejection for any outcome. In other words, it is not clear that there are any outcomes for which our baseline difference-in-differences model is inappropriate. 
In the interest of contributing to the broader debate in the literature about the appropriateness of different age bandwidths when using difference-in-differences models to estimate the effects of the ACA dependent coverage provision, we also run the same set of placebo tests for the most common age ranges used in the literature: treatment group 19-25 and control group 26-34 (Sommers and Kronick, 2012; Sommers et al., 2013; and Chua and Sommers, 2014). We obtain 4 placebo test rejections $(7.5 \%)$ at the $1 \%$ level, $7(13.2 \%)$ at the $5 \%$ level, and $11(20.8 \%)$ at the $10 \%$ level. The full table of results is available upon request.

\section{Heterogeneity}

Having established our baseline results and assessed the validity of our model, we next turn to an examination of heterogeneity in the treatment effects. We considered stratifications by sex, race/ethnicity, education, and state pre-ACA dependent coverage law status, but we did not observe any statistically significant differences in effects across the subgroups for race/ethnicity and pre-ACA law, so we only report the results for the stratifications by sex and education. For education, we stratify into two groups: college graduates and non-college graduates. ${ }^{19}$

Theoretically, the ACA dependent coverage provision could have heterogeneous effects on health-related outcomes for three reasons. First, there could be heterogeneous effects on the probability of having insurance coverage. In the pre-treatment portion of sample, females were more likely to have insurance than males (76\% versus $67 \%$ ), and college graduates were much more likely to have insurance than non-college graduates ( $88 \%$ versus $64 \%$ ). One might therefore expect larger gains in coverage among males and non-college graduates. On the other hand, young adults of high socioeconomic status may be more likely to have parents with

\footnotetext{
${ }^{19}$ Further stratification by education led to estimates that were too imprecise to be useful. Note that we do not include a separate category for current students because our sample only includes those 23 and older, so the proportion of our respondents reporting "student" as their primary occupation is low.
} 
employer-provided coverage, so the gains in coverage could potentially be larger for college graduates.

A second possible source of heterogeneity is that, even if the gains in health insurance are the same among all groups, different groups could respond differently to receiving coverage. For instance, Grossman (1972) argues that education enables individuals to become more efficient producers of health. More education may therefore better equip individuals to make the most out of the newly-acquired insurance (e.g. more easily find providers who accept the insurance, ask better questions at doctor's appointments, or better follow medical advice). Alternatively, the price elasticity of medical care could be strongest among low-income individuals, in which case the effects of obtaining insurance on health care utilization and health could be largest for noncollege graduates. The price elasticity of medical care could also differ by sex. For instance, evidence suggests that females are more risk averse than males (e.g. Jiankoplos and Bernasek, 1998). One might therefore expect females to be more likely to obtain medical care regardless of its price, whereas males might only utilize care if the cost is minimal; i.e. males might have stronger price elasticities. Indeed, in our pre-treatment data uninsured females had higher rates of primary care doctor access, flu vaccination, and well-patient checkups than uninsured males.

Third, as discussed at the beginning of Section IV, the dependent coverage provision could affect health-related outcomes through mechanisms besides the extensive margin of insurance coverage - particularly the intensive margin of coverage - and there could be heterogeneous effects along these dimensions. For instance, suppose part of the reason females and college graduates had lower pre-ACA uninsured rates was because they were more likely to privately purchase a bare-bones, catastrophic plan if they did not have access to employerprovided coverage. In that case, the ACA dependent coverage provision may lead to larger gains 
along the intensive margin of coverage for women and college graduates, leading to larger improvements in health-related outcomes among these groups.

The first two columns of Table 6 report the results for females and males. Males experienced a 2.9 percentage point larger gain in health insurance coverage than females, and the difference is significant at the $1 \%$ level. Moreover, only males experienced statistically significant favorable effects on any outcomes besides insurance coverage. Specifically, males' rates of primary care doctor access, having any exercise, reporting very good/excellent health, and reporting excellent health increased substantially - by 4.6, 1.9, 2.9, and 3.1 percentage points, respectively. These effects are all significantly different from zero, and three of the four (all but very good/excellent health) are also statistically different from the corresponding effects on females. The only statistically significant result for females (besides insurance coverage) is an adverse effect on days with health-related limitations. In sum, the results suggest that males experienced larger improvements in health-related outcomes from the ACA dependent coverage provision than females, and that there appear to be multiple reasons for this heterogeneity. Gains in insurance coverage were larger for males, consistent with them having a higher pre-ACA uninsured rate. Responses to obtaining insurance coverage also appear to have been stronger for males, perhaps indicating a larger price elasticity of demand for medical care.

The last two columns of Table 6 report the results stratifying by college degree attainment. Both groups experienced similar gains in insurance coverage as a result of the ACA dependent coverage provision. However, statistically significant improvements in outcomes besides health insurance are only observed for college graduates. The mandate led to large and significant gains for college graduates in the following outcomes: primary care doctor access (5.1 percentage points), cost being a barrier to care (reduction of 3.4 percentage points), BMI 
(reduction of 0.25 units), obesity (reduction of 1.7 percentage points), and excellent self-reported health (increase of 3.7 percentage points). Besides insurance, the only significant effects for noncollege graduates are unfavorable: a 2.2 percentage point reduction in flu vaccinations and a 1.6 percentage point increase in risky drinking. In short, college graduates experienced greater improvements in health-related outcomes than non-college graduates, and this appears to be due to heterogeneous effects of coverage rather than heterogeneous effects on coverage. This is consistent with a Grossman-style story in which education enables individuals to better take advantage of their health care opportunities. However, the results could also be partly attributable to greater gains along the intensive margin of coverage for college graduates, which we cannot measure in our data. Regardless of the reason, these results suggest that the mandate increases SES-based disparities in health.

\section{Discussion}

The first major insurance expansion under the ACA - a provision requiring insurers to allow young adults to remain on their parents' health insurance until turning 26 - was implemented in September 2010. This paper uses data from the BRFSS to examine the effects of this mandate on various outcomes related to health care access, preventive care utilization, risky health behaviors, and self-assessed health. We implement a difference-in-differences model with individuals slightly below the mandate's age cutoff (ages 23-25) as the treatment group and those slightly above the cutoff (ages 27-29) as the control group.

We first estimate average effects for the entire sample. The results suggest that the ACA dependent coverage provision increased health care access but not utilization of preventive care, had mixed effects on risky health behaviors, and improved health at the high end of the distribution. Specifically, we observe significant and robust favorable effects on health insurance, 
access to a primary care doctor, probability of having excellent self-assessed health, and BMI. However, we also find an adverse effect on risky drinking consistent with ex ante moral hazard and no clear effects on the other outcomes. We then validate our model through a series of placebo tests and show that our classifications of treatment and control groups perform better in these tests that the wider age bandwidths common in the literature. Finally, we conduct subsample analyses, finding particularly striking improvements in outcomes for men and college graduates. Men had larger gains in health insurance coverage than women, and only men experienced statistically significant gains in any outcomes beyond health insurance - specifically primary care access, exercise, and overall self-assessed health. Insurance expansions were similar for college graduates and non-college graduates, but only college graduates experienced significant gains in any other outcomes: primary care access, cost being a barrier to care, BMI, obesity, and overall self-assessed health.

The ACA dependent coverage mandate provides a unique opportunity to study a health insurance intervention specific to young adults as opposed to seniors (Medicare), the poor (Medicaid), or the uninsured population at large (the Massachusetts reform). In general, our results suggest that health insurance affects health-related outcomes of young adults more modestly than prior studies have observed for these other populations. First, we find no evidence of increased preventive care utilization, in contrast to prior results from both Medicaid (Finkelstein et al., 2012) and the Massachusetts reform (Kolstad and Kowalski, 2012). Second, we only find statistically significant improvements in overall self-assessed health at the top of the distribution, as reporting of excellent health increases but there is no clear evidence of an effect on reporting very good or excellent health. We do not observe any gains in the variables reflecting more severe health conditions: days not in good physical health, days not in good 
mental health, and days with functional limitations. This contrasts the clear gains in these same outcomes observed for both Medicaid (Finkelstein et al., 2012) and the Massachusetts reform (Van der Wees et al., 2013; Courtemanche and Zapata, 2014). Interestingly, Chua and Sommers (2014) find that the ACA dependent coverage provision increased the probabilities of selfreporting excellent physical and mental health. Combining their results with ours suggests that physical and mental health did improve, but only at the high end of the distribution.

While our results suggest that health insurance expansions for young adults are less impactful than those for other age groups, it is still important to emphasize that we do observe some improvements in important outcomes, including health care access, excellent self-assessed health, and BMI. One might have initially worried that a coverage expansion for young adults would not lead to any health improvements given the generally good baseline health of this age group.

An important contribution of our paper is that we provide, to our knowledge, the first empirical investigation of ex ante moral hazard that focuses specifically on young adults. We find evidence consistent with ex ante moral hazard in only one domain: risky drinking (binge drinking or excessive number of drinks per month). In contrast, we find evidence that the dependent coverage improved weight-related behaviors while not affecting smoking and pregnancies. Our results therefore suggest that ex ante moral hazard is domain-specific.

Another interesting result is that, since the improvement in health is concentrated among college graduates, the ACA dependent coverage provision appears to increase SES-based disparities in health. This is contrary to the usual impacts of public policies to expand health insurance. Medicaid has been shown to improve at least some health outcomes (Currie and Gruber 1996a and 1996b; Finkelstein et al., 2012; Sommers et al., 2012), implying reduced 
income-based disparities in health. The Massachusetts reform also appears to have reduced income-based disparities, as Courtemanche and Zapata (2014) found the largest gains in selfassessed health among low-income individuals.

Several caveats to our analyses provide directions for future research. First, since we study eighteen different dependent variables, we might expect one or two results to emerge as significant at conventional levels simply by chance. We did not employ multiple hypothesis test adjustments in this paper because, even though such adjustments control the Type I error rate (probability of falsely rejecting any null hypotheses), they do so at the cost of substantially increasing the Type II error rate (probability of failing to reject false null hypotheses) ${ }^{20}$ However, future research should revisit our questions using different data to see if any of our findings could be attributable to chance rather than genuine causal effects of the mandate.

Next, we focus on estimating the ACA dependent coverage provision's effects on 23-25 year olds, ignoring possible effects on 19-22 year olds because of the greater difficulty in finding a suitable control group and the weaker ex ante expectations of significant effects. Further understanding whether benefits accrue to young adults besides $23-25$ year olds is obviously important in order to fully evaluate the policy.

Further research is also necessary to understand the mechanisms through which the mandate improves health. Increased health care utilization is an obvious possibility, but early evidence on the ACA provision's impact on health care consumption is mixed. Akosa Antwi et

\footnotetext{
${ }^{20}$ For instance, the simple Bonferroni correction involves multiplying all p-values by the number of hypotheses being tested, which is eighteen in our case. This would make it virtually impossible to reject any null hypothesis in regressions that already demand quite a bit of the data by including fixed effects and clustering at an aggregated level. It is not clear to us that it would be preferable to, for example, fail to reject five false null hypotheses for the sake of not rejecting one true null hypothesis. This seems especially true in cases such as ours, where null results are an important part of the story. Moreover, we view our analyses as testing for eighteen distinct effects, some of which are more plausible theoretically than others, as opposed to testing for one effect that may manifest itself through eighteen different measures. It is not clear why, for instance, we should inflate the p-values in the health insurance regressions merely because we also study smoking, pregnancies, etc.
} 
al. (2014) report a rise in hospitalizations using administrative data, but Chua and Sommers (2014) find no evidence of changes in survey-based measures of hospital care, primary care, or prescription drug utilization, while we find no significant increases in preventive care. Another possible explanation is that self-assessments of health improve due to a "warm glow" from the peace of mind of having insurance. Finkelstein et al. (2012) proposed this as an explanation for their finding from the Oregon Medicaid experiment that most of the gains in self-assessed health appeared to occur before changes in utilization.

Finally, and critically, our results should not be interpreted as providing a full accounting of the benefits of expanding insurance coverage among young adults. The primary purpose of insurance is to protect individuals from financial risk, and gains along this dimension may be especially substantial for young adults given their relatively low income and wealth levels. Moreover, expanding coverage among young adults is an important component of the overall strategy behind the ACA since it is necessary to offset the additional costs of insuring older and sicker individuals under community rating. In other words, the costs and benefits of the different components of the ACA need to be evaluated together, as the different pieces of the reform are designed to work synergistically.

\section{References}

Acemoglu, D., Finkelstein, A., and Notowidigdo, M. J. (2013). Income and Health Spending: Evidence from Oil Price Shocks. Review of Economics and Statistics, 95, 1079-1095.

Anderson, M., Dobkin, C., and Gross, T. (2012). The Effect of Health Insurance Coverage on the Use of Medical Services. American Economic Journal: Economic Policy 4, 1-27.

Anderson, M., Dobkin, C., and Gross, T. (2014). The Effect of Health Insurance on Emergency Department Visits: Evidence from an Age-Based Eligibility Threshold. Review of Economics and Statistics 96, 189-195.

Angrist, J. D. and Pischke, J. S. (2008). Mostly Harmless Econometrics: An Empiricist's Companion. Princeton, NJ: Princeton University Press. 
Akosa Antwi, Y., Asako, S. M., and Simon, K. (2013). Effects of Federal Policy to Insure Young Adults: Evidence from the 2010 Affordable Care Act Dependent Coverage Mandate. American Economic Journal: Economic Policy, 5, 1-28.

Akosa Antwi, Y., Asako, S. M., and Simon, K. (2014). Access to Health Insurance and the Use of Inpatient Medical Care: Evidence from the Affordable Care Act Young Adult Mandate. National Bureau of Economic Research Working Paper \#20202.

Apouey, B. and Clark, A. E. (2014). Winning Big but Feeling No Better? The Effect of Lottery Prizes on Physical and Mental Health. Health Economics, forthcoming.

Baicker, K., Taubman S. L., Allen, H. L., Bernstein, M., Gruber, J. H., Newhouse, J. P., Schneider, E. C., Wright, B. J., Zaslavsky, A. M., and Finkelstein, A. N. (2013). The Oregon Experiment - Effects of Medicaid on Clinical Outcomes. New England Journal of Medicine, 368, 1713-1722.

Brook, R. H., Ware, J. E., Rogers, W. H., Keeler, E. B., Davies, A., Donald, C., Goldberg, G. A., Lohr, K., Masthay, P. C., and Newhouse, J. P. (1983). Does Free Care Improve Adults' Health? Results From a Randomized Controlled Trial. New England Journal of Medicine, 309, 1426-1434.

Cameron, A. C., Gelback, J.B., and Miller, D.L. (2008). Bootstrap-Based Improvements for Inference with Clustered Errors. Review of Economics and Statistics, 90, 414-427.

Cantor, J. C., Monheit, A. C., DeLia, D., and Lloyd, K. (2012). Early Impact of the Affordable Care Act on Health Insurance Coverage of Young Adults. Health Services Research, 47, 1773-1790.

Card, D., Dobkin, C., and Maestas, N. (2008). The Impact of Nearly Universal Insurance Coverage on Health Care Utilization: Evidence from Medicare. American Economic Review, 98, 2242-2258.

Card, D., Dobkin, C., and Maestas, N. (2009). Does Medicare Save Lives? Quarterly Journal of Economics, 124, 597-636.

Cawley, J. (2004). The Impact of Obesity on Wages. Journal of Human Resources, 39, 451474.

Cawley, J., Moran, J., and Simon, K. (2010). The Impact of Income on the Weight of Elderly Americans. Health Economics, 19, 979-993.

Centers for Disease Control and Prevention (2012). Binge Drinking is Bigger Problem than Previously Thought. Available http://www.cdc.gov/media/releases/2012/p0110 binge drinking.html, accessed 12/13/14. 
Centers for Disease Control and Prevention (2014). Past Weekly Surveillance Reports. Available http://www.cdc.gov/flu/weekly/pastreports.htm, accessed 12/12/14.

Chua, K.P. and Sommers, B.D. (2014). Changes in Health and Medical Spending among Young Adults under Health Reform. Journal of the American Medical Association, 311, 24372439.

Courtemanche, C. and Zapata, D. (2014). Does Universal Coverage Improve Health? The Massachusetts Experience. Journal of Policy Analysis and Management, 33, 36-69.

Courtemanche, C., Heutel, G., and McAlvanah, P. (forthcoming). Impatience, Incentives, and Obesity. Economic Journal.

Courtemanche, C., Pinkston, J., and Stewart, J. (2014). Adjusting Body Mass for Measurement Error with Invalid Validation Data. National Bureau of Economic Research Working Paper \#19928.

Currie, J. and Gruber J. (1996a). Health Insurance Eligibility, Utilization of Medical Care, and Child Health. Quarterly Journal of Economics, 111, 431-466.

Currie, J. and Gruber, J. (1996b). Saving Babies: The Efficacy and Cost of Recent Changes in the Medicaid Eligibility of Pregnant Women. Journal of Political Economy, 104, 12631296.

Dave, D. and Kaestner, R. (2009). Health Insurance and Ex Ante Moral Hazard: Evidence from Medicare. International Journal of Health Care Finance and Economics, 9, 367-390.

Dafny, L. and Gruber, J. (2005). Public Insurance and Child Hospitalizations: Access and Efficiency Effects. Journal of Public Economics, 89, 109-129.

DeNavas-Walt, C., Proctor, B. D., and Smith, J. C. (2010). Income, Poverty, and Health Insurance Coverage in the United States: 2009. U.S. Census Bureau. Washington, D.C.: U.S. Government Printing Office, 1-79.

DeSalvo, K. B., Bloser, N., Reynolds, K., He, J., and Muntner, P. (2006). Mortality Prediction with a Single General Self-Rated Health Question. A Meta-Analysis. Journal of General Internal Medicine, 21, 267-275.

Ehrlick, I. and Becker, G. S. (1972). Market Insurance, Self-Insurance, and Self-Protection. Journal of Political Economy, 80, 623-648.

Finkelstein, A.N, and McKnight R. (2008). What Did Medicare Do? The Initial Impact of Medicare on Mortality and Out of Pocket Medical Spending. Journal of Public Economics, 92, 1644-1668. 
Finkelstein, A. N., Taubman, S., Wright, B., Bernstein, M., Gruber, J., Newhouse, J. P., Allen, H., Baicker, K., and The Oregon Health Study Group. (2012). The Oregon Health Insurance Experiment: Evidence from the First Year. Quarterly Journal of Economics, 127, 1057-1106.

Frijters, P., Haisken-DeNew, J. P., and Shields, M. (2005). The Causal Effect of Income on Health: Evidence from German Reunification. Journal of Health Economics, 24, 9971017.

Grossman, M. (1972). On the Concept of Health Capital and Demand for Health. Journal of Political Economy, 80, 223-255.

Gruber, J. (2011). The Impacts of the Affordable Care Act: How Reasonable Are the Projections? National Bureau of Economic Research Working Paper \#17168.

Idler, E. L. and Benyamini, Y. (1997). Self-Rated Health and Mortality: a Review of TwentySeven Community Studies. Journal of Health and Social Behavior, 38, 21-37.

Jianakoplos, N.A. and Bernasek, A. (1998). Are Women More Risk Averse? Economic Inquiry, $36,620-630$.

Kolstad, J.T. and Kowalski, A.E. (2012). The Impact of Health Care Reform on Hospital and Preventive Care: Evidence from Massachusetts. Journal of Public Economics, 96, 909929.

Lakdawalla, D. and Philipson, T. (2002). The Growth of Obesity and Technological Change: A Theoretical and Empirical Investigation. National Bureau of Economic Research Working Paper \# 8946.

Levine, P. B., McKnight R., and Heep S. (2011). How Effective are Public Policies to Increase Health Insurance Coverage among Young Adults? American Economic Journal: Economic Policy, 3 (1): 129-156.

Lichtenberg, F.R. (2002). The Effects of Medicare on Health Care Utilization and Outcomes. In Frontiers in Health Policy Research, Volume 5, Cambridge, MA: MIT Press.

Lindahl, M. (2005). "Estimating the Effect of Income on Health and Mortality Using Lottery Prizes as an Exogenous Source of Variation in Income." Journal of Human Resources, 40(1), 144-168.

Manning, W. G., Newhouse, J. P., Duan, N., Keeler, E. B., Leibowitz, A., and Marquis, M.S. (1987). Health Insurance and the Demand for Medical Care: Evidence from a Randomized Experiment. American Economic Review, 77(3), 251-277.

Miller, S. (2011). The Effect of Insurance on Outpatient Emergency Room Visits: An Analysis of the 2006 Massachusetts Health Reform. Journal of Public Economics, 96, 893-908. 
Miller, S. (2012). The Impact of the Massachusetts Health Care Reform on Health Care Use among Children. American Economic Review: Papers and Proceedings, 102(3), 502-507.

Monheit, A., Cantor, J., DeLia, D. and Belloff, D. (2011). How Have State Policies to Expand Dependent Coverage Affected the Health Insurance Status of Young Adults? Health Services Research, 46, 251-267.

National Conference of State Legislatures. (2010). "Covering Young Adults through their Parents' or Guardians' Health Policy." Retrieved from http://www.ncsl.org/research/health/dependent-health-coverage-stateimplementation.aspx

National Highway Traffic Safety Administration (2014). "Traffic Safety Facts 2012: AlcoholImpaired Driving." Available at http://www-nrd.nhtsa.dot.gov/Pubs/811870.pdf, accessed 12/14/14.

National Institute on Alcohol Abuse and Alcoholism (2013). "College Drinking." Available at http://pubs.niaaa.nih.gov/publications/CollegeFactSheet/CollegeFactSheet.pdf, accessed $12 / 14 / 14$.

Phillips A. C., Der, G., and Carroll, D. (2010). Self-Reported Health, Self-Reported Fitness, and all-Cause Mortality: Prospective Cohort Study. British Journal of Health Psychology, 15, 337-346.

Ruhm, C. J. (2000). Are Recessions Good For Your Health? Quarterly Journal of Economics, 115(2), 617-650.

Ruhm, C. J. (2002). Does Drinking Really Decrease in Bad Times? Journal of Health Economics, 21(4), 659-678.

Ruhm, C. J. (2005). Healthy Living In Hard Times. Journal of Health Economics, 24(2), 341363.

Ruhm, C. J. (2013). Recessions, Healthy No More? National Bureau of Economic Research Working Paper \#19287.

Schmeiser, M. D. (2009). Expanding Wallets and Waistlines: The Impact of Family Income on the BMI of Women and Men Eligible for the Earned Income Tax Credit. Health Economics, 18, 1277-1294.

Slusky, D. J. G. (2013). Revisiting the Labor Effects of the Affordable Care Act. Princeton University Working Paper.

Snyder, S. E. and Evans, W. N. (2006). The Impact of Income on Mortality: Evidence from the Social Security Notch. Review of Economics and Statistics, 88(3), 482-495. 
Sommers, B. D., Baicker, K., and Epstein, A. M. (2012). Mortality and Access to Care among Adults after State Medicaid Expansions. New England Journal of Medicine, 367, 10251034.

Sommers, B. D., Buchmueller, T., Decker, S. L., Carey, C. and Kronick, R. (2013). The Affordable Care Act Has Led to Significant Gains in Health Insurance and Access to Care for Young Adults. Health Affairs, 32, 165-174.

Sommers, B. D., and Kronick, R. (2012). The Affordable Care Act and Insurance Coverage for Young Adults. Journal of the American Medical Association, 307 (9): 913-4.

Sommers, B. D., Long, S.K., and Baicker, K. (2014). Changes in Mortality After Massachusetts Health Care Reform: A Quasi-Experimental Study. Annals of Internal Medicine, 160(9), 585-593.

Taubman, S.L., Allen, H.L., Wright, B.J., Baicker, K., and Finkelstein, A.N. (2014). Medicaid Increases Emergency-Department Use: Evidence from Oregon's Health Insurance Experiment. Science, 343, 263-268.

Tekin, E., McClellan, C., and Minyard, K.J. (2013). Health and Health Behaviors during the Worst of Times: Evidence from the Great Recession. National Bureau of Economic Research Working Paper \#19234.

Van der Wees, P.J., Zaslavsky, A.M., and Ayanian, J.Z. (2013). Improvements in Health Status after Massachusetts Health Care Reform. Milbank Quarterly, 91, 663-689. 


\section{Figure 1 -- Trends in Access to Care and Preventive Care Variables by Age Group}

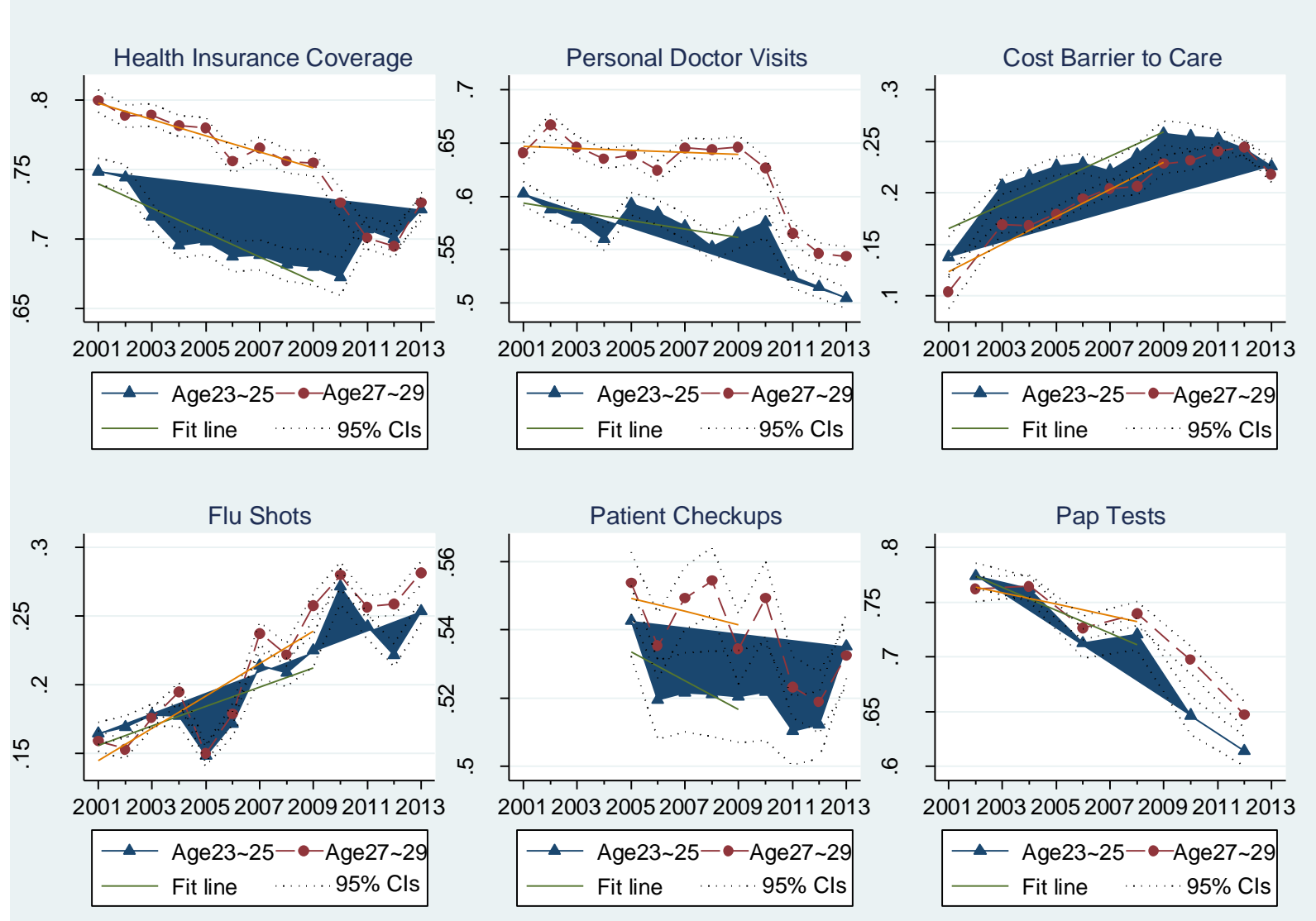




\section{Figure 2 -- Trends in Health Behavior Variables by Age Group}
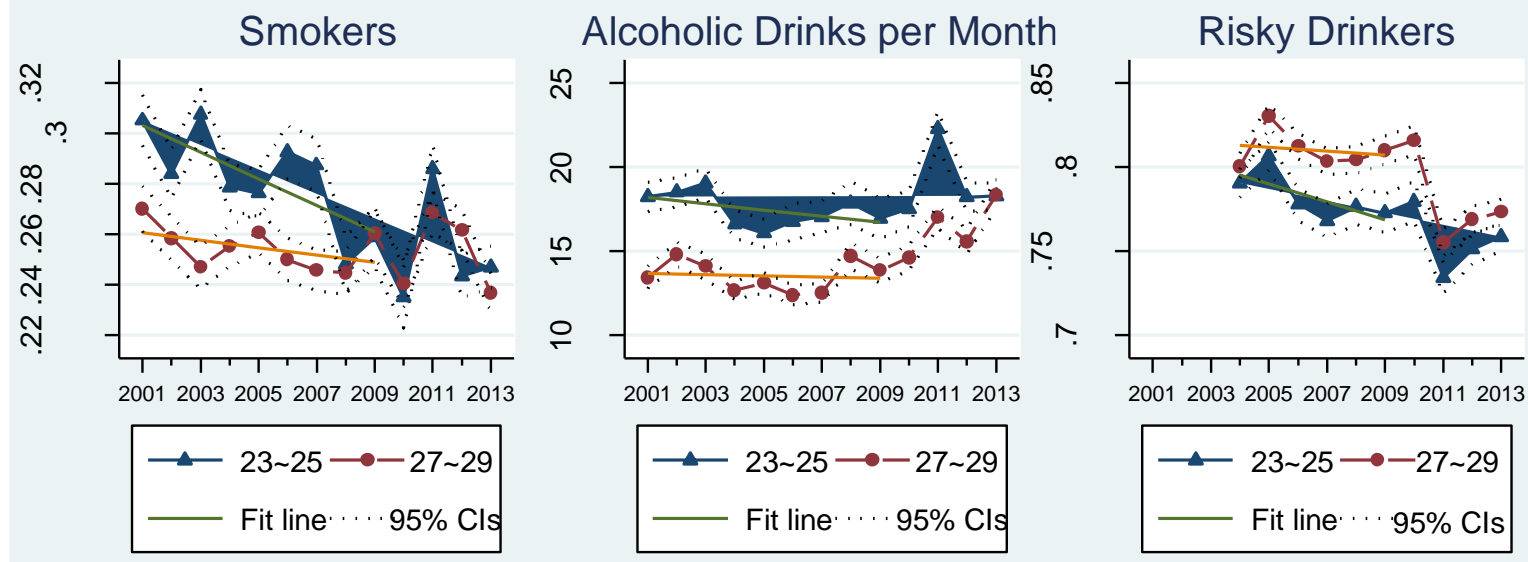

2001200320052007200920112013

$\longrightarrow$ 23 25 $\longrightarrow-27 \sim 29$

Fit line . . . 95\% Cls

Body Mass Index

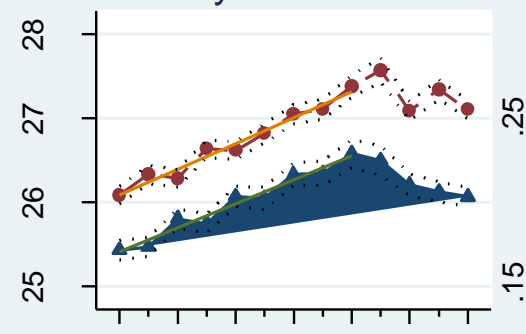

2001200320052007200920112013

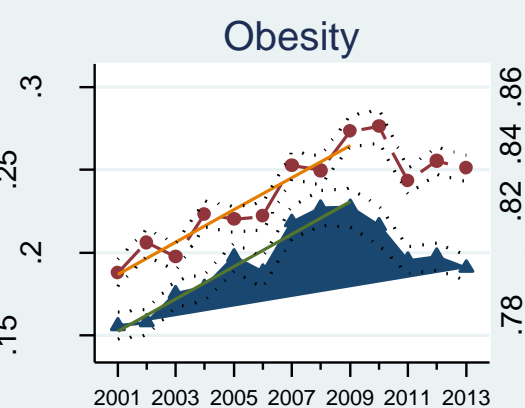

Any Exercise

$\longrightarrow$ 23 25 $\longrightarrow-27 \sim 29$
- Fit line $\cdots . .95 \%$ Cls

2001200320052007200920112013

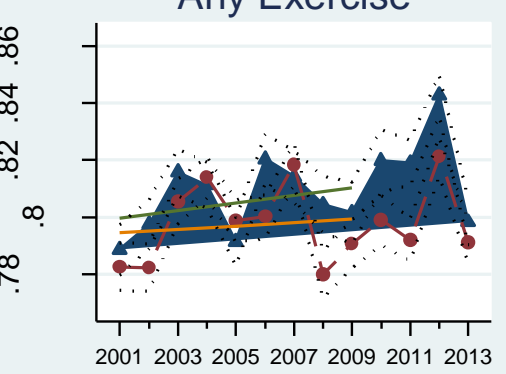

$\longrightarrow$ 23 25 $\longrightarrow-27 \sim 29$

Fit line .... 95\% Cls

$\longrightarrow 23 \sim 25 \longrightarrow-27 \sim 29$ Fit line $95 \% \mathrm{Cls}$

\section{Pregnancy}

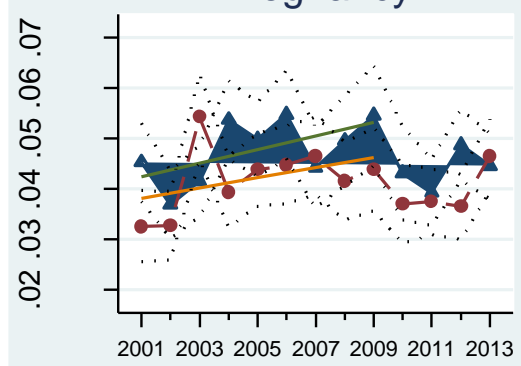

$\longrightarrow$ 23 25 $-27 \sim 29$

Fit line $\cdots . . .95 \% \mathrm{Cls}$ 


\section{Figure 3 -- Trends in Self-Assessed Health Variables by Age Group}

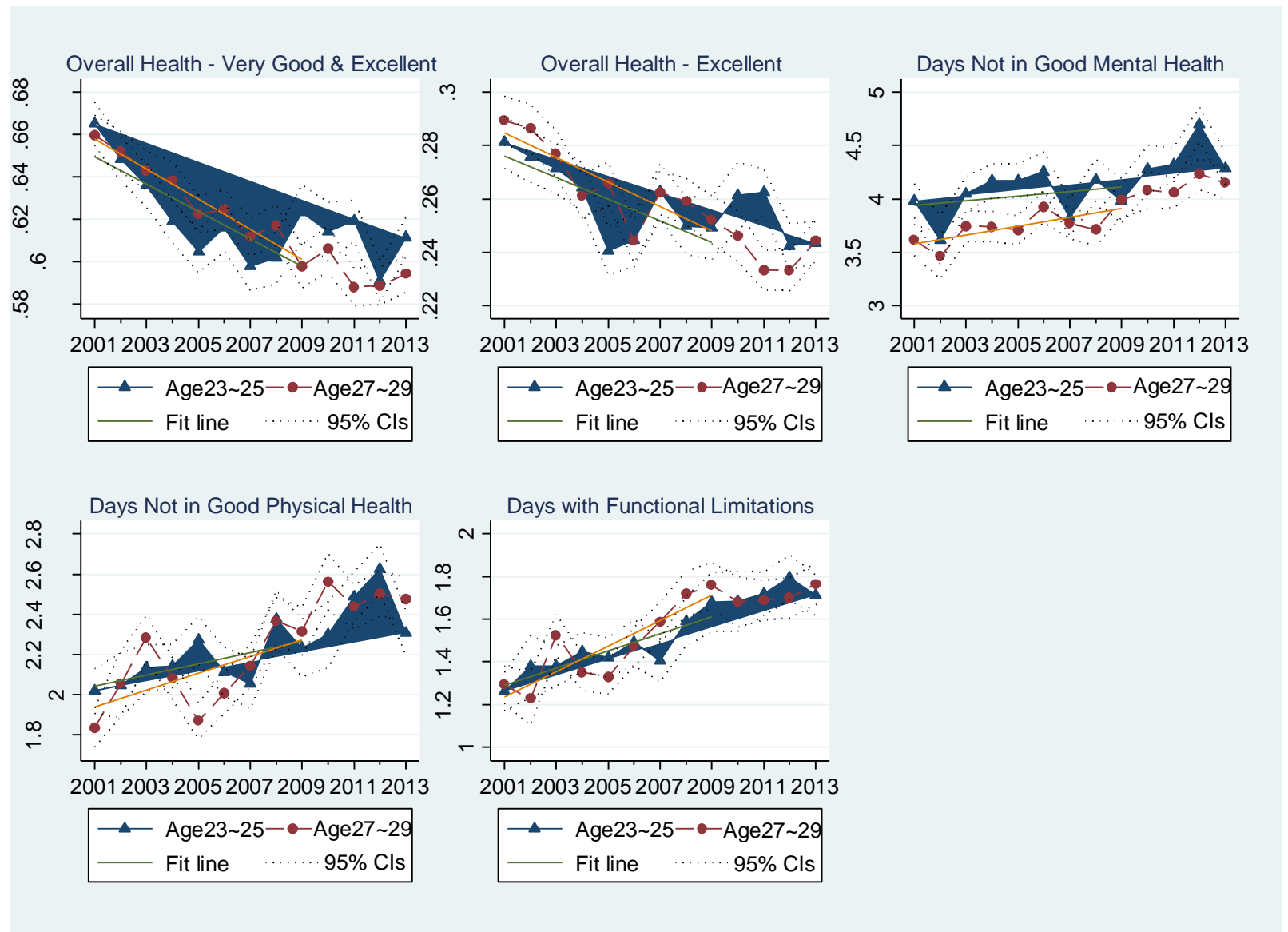


Table 1 - Sample Sizes for Different Outcomes

\begin{tabular}{lccc}
\hline Outcome Variable & Total & $\begin{array}{c}\text { Treatment } \\
(23-25)\end{array}$ & $\begin{array}{c}\text { Control } \\
(27-29)\end{array}$ \\
\hline Health care access & & & \\
$\quad$ Any health insurance coverage & 126,702 & 53,057 & 73,645 \\
$\quad$ Any primary care doctor & 118,392 & 49,520 & 68,872 \\
$\quad$ Cost prevented care in past year & 107,831 & 45,041 & 62,790 \\
Preventive care utilization & & & \\
Flu vaccination in past year & 118,394 & 49,502 & 68,892 \\
Well-patient checkup in past year & 107,931 & 45,085 & 62,846 \\
Pap test in past year (women only) & 26,919 & 10,799 & 16,120 \\
Risky health behaviors & & & \\
Currently smokes cigarettes & 125,616 & 52,607 & 73,009 \\
Alcoholic drinks in past 30 days & 120,958 & 50,521 & 70,437 \\
Risky drinker in past 30 days & 120,037 & 50,110 & 69,927 \\
Body mass index & 120,373 & 50,529 & 69,844 \\
Obese & 120,373 & 50,529 & 69,844 \\
Any exercise in past 30 days & 122,720 & 51,337 & 71,383 \\
Pregnancy (unmarried women only) & 39,499 & 19,610 & 19,889 \\
Self-assessed health & & & \\
Overall health very good or excellent & 126,662 & 53,102 & 73,560 \\
Overall health excellent & 126,662 & 53,102 & 73,560 \\
Days of last 30 not in good mental health & 124,773 & 52,386 & 72,387 \\
Days of last 30 not in good physical health & 124,861 & 52,387 & 72,474 \\
Days of last 30 with health-related limitations & 125,365 & 52,615 & 72,750 \\
\hline
\end{tabular}

${ }^{+}$The pap test variable is only available in even-numbered years, reducing the sample size for that outcome. 
Table 2 - Pre-Treatment Means and Standard Deviations for Control Variables

\begin{tabular}{|c|c|c|}
\hline Control Variable & Treatment (Ages 23-25) & Control (Ages 27-29) \\
\hline \multicolumn{3}{|l|}{ Age dummies (age $=23$ is omitted) } \\
\hline Age $=24$ & $0.349(0.477)$ & -- \\
\hline Age $=25$ & $0.322(0.467)$ & -- \\
\hline Age $=27$ & -- & $0.310(0.462)$ \\
\hline Age $=28$ & -- & $0.343(0.475)$ \\
\hline Age $=29$ & -- & $0.347(0.476)$ \\
\hline Female & $0.505(0.500)$ & $0.508(0.500)$ \\
\hline \multicolumn{3}{|c|}{ Race/ethnicity dummies (non-Hispanic white is omitted) } \\
\hline Non-Hispanic black & $0.112(0.316)$ & $0.116(0.320)$ \\
\hline Hispanic & $0.224(0.417)$ & $0.209(0.407)$ \\
\hline Other than black, Hispanic, or white & $0.087(0.282)$ & $0.077(0.266)$ \\
\hline Currently married & $0.305(0.460)$ & $0.564(0.496)$ \\
\hline \multicolumn{3}{|c|}{ Education dummies (less than high school degree is omitted) } \\
\hline High school degree but no further & $0.283(0.450)$ & $0.257(0.437)$ \\
\hline Some college but no four-year degree & $0.299(0.458)$ & $0.271(0.444)$ \\
\hline College graduate & $0.303(0.459)$ & $0.364(0.481)$ \\
\hline \multicolumn{3}{|c|}{ Household income dummies (less than $\$ 10,000$ is omitted) } \\
\hline Between $\$ 10,000$ and $\$ 15,000$ & $0.068(0.252)$ & $0.049(0.216)$ \\
\hline Between $\$ 15,000$ and $\$ 20,000$ & $0.102(0.303)$ & $0.077(0.267)$ \\
\hline Between $\$ 20,000$ and $\$ 25,000$ & $0.116(0.321)$ & $0.097(0.296)$ \\
\hline Between $\$ 25,000$ and $\$ 35,000$ & $0.144(0.351)$ & $0.129(0.335)$ \\
\hline Between $\$ 35,000$ and $\$ 50,000$ & $0.166(0.372)$ & $0.165(0.371)$ \\
\hline Between $\$ 50,000$ and $\$ 75,000$ & $0.143(0.350)$ & $0.187(0.390)$ \\
\hline$\$ 75,000$ and over & $0.186(0.389)$ & $0.240(0.427)$ \\
\hline \multicolumn{3}{|c|}{ Number of children in household dummies (0 is omitted) } \\
\hline One child & $0.230(0.421)$ & $0.235(0.424)$ \\
\hline Two children & $0.159(0.366)$ & $0.233(0.423)$ \\
\hline Three children & $0.055(0.229)$ & $0.110(0.313)$ \\
\hline Four children & $0.018(0.133)$ & $0.038(0.192)$ \\
\hline Five or more children & $0.008(0.090)$ & $0.016(0.124)$ \\
\hline Cell phone only & $0.703(0.457)^{+}$ & $0.678(0.467)^{+}$ \\
\hline Student & $0.109(0.312)$ & $0.054(0.226)$ \\
\hline Unemployed & $0.111(0.314)$ & $0.093(0.290)$ \\
\hline State unemployment rate & $7.032(2.615)$ & $7.186(2.666)$ \\
\hline Pre-ACA state mandate & $0.220(0.415)$ & $0.033(0.179)$ \\
\hline
\end{tabular}

Notes: BRFSS sampling weights are used. Means are reported, with standard deviations in parentheses. ${ }^{+}$indicates the summary statistics are from 2011-2013, since the variable is 0 for all respondents in all prior years. 
Table 3 - Means and Standard Deviations for Outcome Variables

\begin{tabular}{|c|c|c|c|c|c|}
\hline \multirow[b]{2}{*}{ Outcome Variable } & \multicolumn{2}{|c|}{ Pre-Treatment Period } & \multicolumn{2}{|c|}{ Post-Treatment Period } & \multirow{2}{*}{$\begin{array}{l}\text { Difference-in- } \\
\text { Differences }\end{array}$} \\
\hline & $\begin{array}{c}\text { Treatment (Ages } \\
23-25)\end{array}$ & $\begin{array}{c}\text { Control (Ages 27- } \\
29 \text { ) }\end{array}$ & $\begin{array}{c}\text { Treatment (Ages } \\
23-25)\end{array}$ & $\begin{array}{c}\text { Control (Ages 27- } \\
\text { 29) }\end{array}$ & \\
\hline \multicolumn{6}{|l|}{ Health care access } \\
\hline Any health insurance coverage & $0.680(0.466)$ & $0.753(0.431)$ & $0.709(0.454)$ & $0.708(0.455)$ & $0.073(0.018)^{* * *}$ \\
\hline Any primary care doctor & $0.564(0.496)$ & $0.641(0.480)$ & $0.519(0.500)$ & $0.558(0.497)$ & $0.038(0.010)^{* *}$ \\
\hline Cost prevented care in past year & $0.241(0.427)$ & $0.216(0.411)$ & $0.240(0.427)$ & $0.235(0.424)$ & $-0.020(0.014)$ \\
\hline \multicolumn{6}{|l|}{ Preventive care utilization } \\
\hline Flu vaccination in past year & $0.225(0.418)$ & $0.246(0.431)$ & $0.239(0.426)$ & $0.265(0.441)$ & $-0.006(0.009)$ \\
\hline Well-patient checkup in past year & $0.521(0.500)$ & $0.545(0.498)$ & $0.524(0.499)$ & $0.529(0.499)$ & $0.019(0.011)$ \\
\hline Pap test in past year & $0.693(0.461)$ & $0.724(0.447)$ & $0.614(0.487)$ & $0.647(0.478)$ & $-0.002(0.013)$ \\
\hline \multicolumn{6}{|l|}{ Risky health behaviors } \\
\hline Currently smokes cigarettes & $0.260(0.432)$ & $0.249(0.432)$ & $0.257(0.437)$ & $0.254(0.435)$ & $-0.009(0.012)$ \\
\hline Alcoholic drinks in past 30 days & $17.359(43.926)$ & $13.883(34.703)$ & $19.481(43.947)$ & $16.841(40.916)$ & $-0.836(0.889)$ \\
\hline Risky drinker in past 30 days & $0.775(0.418)$ & $0.807(0.394)$ & $0.749(0.434)$ & $0.769(0.422)$ & $0.013(0.005) *$ \\
\hline Body mass index & $26.404(5.807)$ & $27.253(6.031)$ & $26.167(6.019)$ & $27.192(6.142)$ & $-0.177(0.050)^{* *}$ \\
\hline Obese & $0.222(0.415)$ & $0.262(0.440)$ & $0.197(0.398)$ & $0.252(0.434)$ & $-0.014(0.003) * * *$ \\
\hline Any exercise in past 30 days & $0.810(0.392)$ & $0.799(0.401)$ & $0.819(0.385)$ & $0.799(0.401)$ & $0.009(0.005)$ \\
\hline Pregnancy & $0.048(0.215)$ & $0.043(0.203)$ & $0.044(0.205)$ & $0.040(0.195)$ & $-0.001(0.004)$ \\
\hline \multicolumn{6}{|l|}{ Self-assessed health } \\
\hline Overall health very good/excellent & $0.607(0.488)$ & $0.610(0.488)$ & $0.608(0.488)$ & $0.589(0.492)$ & $0.022(0.011)$ \\
\hline Overall health excellent & $0.255(0.436)$ & $0.257(0.437)$ & $0.250(0.433)$ & $0.236(0.425)$ & $0.017(0.003) * * *$ \\
\hline Days not in good mental health & $4.050(7.638)$ & $3.844(7.680)$ & $4.410(8.067)$ & $4.165(8.063)$ & $0.040(0.162)$ \\
\hline Days not in good physical health & $2.240(5.526)$ & $2.303(5.815)$ & $2.446(5.999)$ & $2.484(6.170)$ & $0.025(0.053)$ \\
\hline Days with health-related limitations & $1.589(4.757)$ & $1.664(5.177)$ & $1.727(5.131)$ & $1.739(5.332)$ & $0.063(0.104)$ \\
\hline
\end{tabular}

Notes: Standard errors, heteroskedasticity-robust and clustered by age, are in parentheses. BRFSS sampling weights are used. Means are reported, with standard deviations in parentheses. $* * *$ indicates the difference-in-difference is significant at the $1 \%$ level; ** 5\% level; * $10 \%$ level. 
Table 4 - Difference-in-Difference Regression Estimates of Effects of ACA Dependent Coverage Mandate

\begin{tabular}{|c|c|c|c|c|c|c|}
\hline Outcome Variable & Baseline Model & $\begin{array}{l}\text { Demographic } \\
\text { Controls Only }\end{array}$ & Start in 2004 & Start in 2001 & Drop 3/10-12/10 & Collapsed Data \\
\hline \multicolumn{7}{|l|}{ Health care access } \\
\hline Any health insurance & $0.061(0.017)^{* *}[0.130]$ & $0.067(0.018)^{* *}$ & $0.059(0.013)^{* * *}$ & $0.055(0.012)^{* * *}$ & $0.064(0.016)^{* * *}$ & $0.061(0.015)^{* * *}$ \\
\hline Any primary doctor & $0.032(0.010)^{* *}[0.065]$ & $0.034(0.010)^{* *}$ & $0.020(0.006)^{* *}$ & $0.021(0.006)^{* *}$ & $0.033(0.009)^{* *}$ & $0.029(0.011)^{* *}$ \\
\hline Cost prevented care & $-0.019(0.014)[-0.044]$ & $-0.019(0.014)$ & $-0.022(0.015)$ & $-0.023(0.015)$ & $-0.020(0.015)$ & $-0.016(0.011)$ \\
\hline \multicolumn{7}{|l|}{ Preventive care utilization } \\
\hline Flu vaccination & $-0.014(0.007)[-0.033]$ & $-0.011(0.008)$ & $-0.017(0.009)$ & $-0.018(0.008)^{*}$ & $-0.014(0.008)$ & $-0.020(0.006)^{* *}$ \\
\hline Well-patient checkup & $0.013(0.011)[0.026]$ & $0.015(0.010)$ & $0.011(0.010)$ & $0.011(0.010)$ & $0.017(0.010)$ & $0.011(0.006)$ \\
\hline Pap test & $-0.004(0.015)[-0.009]$ & $-0.003(0.014)$ & $-0.019(0.010)$ & $-0.025(0.015)^{* *}$ & $-0.015(0.015)$ & $0.002(0.008)$ \\
\hline \multicolumn{7}{|l|}{ Risky health behaviors } \\
\hline Currently smokes & $0.003(0.007)$ [0.007] & $-0.006(0.010)$ & $-0.001(0.004)$ & $-0.008(0.005)$ & $-0.001(0.006)$ & $0.005(0.007)$ \\
\hline Drinks per month & $0.120(0.906)[0.003]$ & $-0.468(0.887)$ & $-0.429(0.604)$ & $-0.597(0.590)$ & $0.083(0.840)$ & $0.011(0.929)$ \\
\hline Risky drinker & $0.011(0.003)^{* *}[0.026]$ & $0.008(0.004)^{*}$ & $0.009(0.003)^{* *}$ & $0.009(0.007)^{* *}$ & $0.014(0.003)^{* * *}$ & $0.009(0.003)^{* *}$ \\
\hline Body mass index & $-0.098(0.029) * *[-0.017]$ & $-0.175(0.045)^{* *}$ & $-0.124(0.062)$ & $-0.169(0.061)^{* *}$ & $-0.173(0.074)^{*}$ & $-0.118(0.033)^{* * *}$ \\
\hline Obese & $-0.009(0.008)[-0.022]$ & $-0.014(0.005)^{* *}$ & $-0.010(0.007)$ & $-0.011(0.008)$ & $-0.013(0.006)^{*}$ & $-0.010(0.004)^{* *}$ \\
\hline Any exercise & $0.003(0.004)[0.008]$ & $0.008(0.007)$ & $0.005(0.003)$ & $0.004(0.004)$ & $0.001(0.005)$ & $0.007(0.003)^{* *}$ \\
\hline Pregnancy & $-0.003(0.005)[-0.014]$ & $-0.002(0.005)$ & $-0.004(0.004)$ & $-0.002(0.004)$ & $-0.003(0.005)$ & $-0.002(0.004)$ \\
\hline \multicolumn{7}{|l|}{ Self-assessed health } \\
\hline Very good/exc. Health & $0.015(0.011)[0.031]$ & $0.018(0.010)$ & $0.016(0.011)$ & $0.015(0.008)$ & $0.011(0.010)$ & $0.014(0.009)$ \\
\hline Excellent health & $0.014(0.005) * *[0.032]$ & $0.014(0.003)^{* * *}$ & $0.013(0.004)^{* *}$ & $0.014(0.005)^{* *}$ & $0.014(0.006)^{*}$ & $0.015(0.004)^{* * *}$ \\
\hline Days not good mental & $0.081(0.158)[0.010]$ & $0.064(0.144)$ & $0.050(0.144)$ & $0.036(0.116)$ & $0.156(0.156)$ & $0.084(0.127)$ \\
\hline Days not good phys. & $0.059(0.068)[0.011]$ & $0.045(0.046)$ & $-0.022(0.079)$ & $-0.014(0.076)$ & $0.075(0.028)^{* *}$ & $0.028(0.063)$ \\
\hline Days health limitations & $0.122(0.099)[0.025]$ & $0.102(0.093)$ & $0.073(0.109)$ & $0.065(0.094)$ & $0.201(0.107)$ & $0.101(0.086)$ \\
\hline
\end{tabular}

Notes: *** indicates significant at the $1 \%$ level; ** 5\% level; * 10\% level. Standard errors, heteroskedasticity-robust and clustered by age, are in parentheses. All regressions include the controls plus age, state, and time fixed effects. BRFSS sampling weights are used. For the baseline regression, effect sizes in standard deviations of the dependent variable (for the treatment group in the pre-treatment period) are in brackets. 
Table 5 - Placebo Regressions

\begin{tabular}{|c|c|c|c|}
\hline Outcome Variable & $\begin{array}{c}\text { 2003-2009 } \\
\text { Treatment 10/06 }\end{array}$ & $\begin{array}{c}2002-2008 \\
\text { Treatment } 10 / 05\end{array}$ & $\begin{array}{c}\text { 2001-2007 } \\
\text { Treatment 10/04 }\end{array}$ \\
\hline \multicolumn{4}{|l|}{ Health care access } \\
\hline Any health insurance coverage & $-0.002(0.005)$ & $0.002(0.008)$ & $-0.009(0.007)$ \\
\hline Any primary care doctor & $-0.008(0.014)$ & $0.002(0.007)$ & $0.019(0.011)$ \\
\hline Cost prevented care in past year & $-0.007(0.011)$ & $-0.017(0.013)$ & $-0.013(0.007)$ \\
\hline \multicolumn{4}{|l|}{ Preventive care utilization } \\
\hline Flu vaccination in past year & $-0.013(0.016)$ & $-0.007(0.008)$ & $-0.001(0.007)$ \\
\hline Well-patient checkup in past year & $0.002(0.014)$ & $-0.008(0.014)$ & -- \\
\hline Pap test in past year & $-0.012(0.014)$ & $-0.024(0.022)$ & $-0.027(0.025)$ \\
\hline \multicolumn{4}{|l|}{ Risky health behaviors } \\
\hline Currently smokes cigarettes & $-0.019(0.007)^{* *}$ & $-0.006(0.009)$ & $-0.007(0.008)$ \\
\hline Alcoholic drinks in past 30 days & $-1.648(1.035)$ & $-0.659(0.584)$ & $-1.146(0.788)$ \\
\hline Risky drinker in past 30 days & $-0.001(0.006)$ & $-0.014(0.007)^{*}$ & $-0.009(0.011)$ \\
\hline Body mass index & $-0.001(0.146)$ & $-0.023(0.196)$ & $-0.082(0.145)$ \\
\hline Obese & $0.002(0.008)$ & $0.005(0.011)$ & $0.0005(0.009)$ \\
\hline Any exercise in past 30 days & $0.008(0.008)$ & $0.008(0.005)$ & $-0.004(0.005)$ \\
\hline Pregnancy & $0.011(0.010)$ & $0.005(0.012)$ & $-0.002(0.007)$ \\
\hline \multicolumn{4}{|l|}{ Self-assessed health } \\
\hline Overall health very good/excellent & $0.011(0.003)^{* *}$ & $0.002(0.009)$ & $0.004(0.009)$ \\
\hline Overall health excellent & $0.004(0.005)$ & $0.009(0.005)$ & $0.006(0.008)$ \\
\hline Days not in good mental health & $-0.064(0.174)$ & $-0.005(0.232)$ & $-0.054(0.143)$ \\
\hline Days not in good physical health & $-0.041(0.109)$ & $0.034(0.121)$ & $0.165(0.107)$ \\
\hline Days with health-related limitations & $-0.039(0.084)$ & $-0.043(0.051)$ & $0.017(0.060)$ \\
\hline
\end{tabular}

Notes: *** indicates significant at the $1 \%$ level; ** 5\% level; * $10 \%$ level. Standard errors, heteroskedasticity-robust and clustered by age, are in parentheses. All regressions include the controls plus age, state, and time fixed effects. BRFSS sampling weights are used. 
Table 6 - Heterogeneity by Sex and Education

\begin{tabular}{|c|c|c|c|c|}
\hline \multirow[b]{2}{*}{ Outcome Variable } & \multicolumn{2}{|c|}{ Sex } & \multicolumn{2}{|c|}{ Education } \\
\hline & Female & Male & $\begin{array}{c}\text { Not College } \\
\text { Graduate }\end{array}$ & College Graduate \\
\hline \multicolumn{5}{|l|}{ Health care access } \\
\hline Any health insurance coverage & $0.045(0.017)^{* *}$ & $0.074(0.016)^{* * * *^{+++}}$ & $0.067(0.019)^{* *}$ & $0.061(0.013)^{* * *}$ \\
\hline Any primary care doctor & $0.016(0.009)$ & $0.046(0.012)^{* *^{+}}$ & $0.025(0.012)$ & $0.051(0.006)^{* * * *^{++}}$ \\
\hline Cost prevented care in past year & $-0.019(0.021)$ & $-0.016(0.013)$ & $-0.014(0.017)$ & $-0.034(0.009)^{* *}$ \\
\hline \multicolumn{5}{|l|}{ Preventive care utilization } \\
\hline Flu vaccination in past year & $-0.020(0.012)$ & $-0.012(0.010)$ & $-0.022(0.008)^{* *}$ & $0.003(0.009)$ \\
\hline Well-patient checkup in past year & $0.013(0.014)$ & $0.013(0.016)$ & $0.006(0.019)$ & $0.035(0.016)$ \\
\hline Pap test in past year & $-0.004(0.015)$ & -- & $-0.007(0.021)$ & $0.008(0.028)$ \\
\hline \multicolumn{5}{|l|}{ Risky health behaviors } \\
\hline Currently smokes cigarettes & $0.011(0.011)$ & $-0.004(0.016)$ & $0.001(0.008)$ & $0.002(0.006)$ \\
\hline Alcoholic drinks in past 30 days & $-0.117(0.441)$ & $0.359(1.559)$ & $-0.068(1.171)$ & $0.398(0.985)$ \\
\hline Risky drinker & $0.009(0.012)$ & $0.015(0.014)$ & $0.016(0.004)^{* * *}$ & $-0.007(0.007)$ \\
\hline Body mass index & $-0.133(0.153)$ & $0.018(0.160)$ & $0.001(0.050)$ & $-0.254(0.096)^{* *}$ \\
\hline Obese & $-0.010(0.010)$ & $-0.005(0.012)$ & $-0.004(0.009)$ & $-0.017(0.004)^{* * *}$ \\
\hline Any exercise in past 30 days & $-0.010(0.007)$ & $0.019(0.004)^{* * *++}$ & $0.001(0.006)$ & $0.010(0.005)$ \\
\hline Pregnancy & $-0.003(0.005)$ & -- & $-0.005(0.006)$ & $-0.001(0.006)$ \\
\hline \multicolumn{5}{|l|}{ Self-assessed health } \\
\hline Overall health very good or excellent & $0.001(0.022)$ & $0.029(0.009)^{* *}$ & $0.007(0.009)$ & $0.029(0.017)$ \\
\hline Overall health excellent & $-0.003(0.009)$ & $0.031(0.005)^{* * *++}$ & $0.002(0.006)$ & $0.037(0.012)^{* *}$ \\
\hline Days of last 30 not in good mental health & $0.100(0.196)$ & $0.083(0.160)$ & $0.259(0.154)$ & $-0.323(0.193)^{+++}$ \\
\hline Days of last 30 not in good physical health & $0.109(0.081)$ & $-0.011(0.167)$ & $0.211(0.145)$ & $-0.262(0.166)$ \\
\hline Days of last 30 with health-related limitations & $0.347(0.110)^{* *}$ & $-0.102(0.206)$ & $0.265(0.161)$ & $-0.149(0.096)$ \\
\hline
\end{tabular}

Notes: +++ difference between effects on subgroups is significant at the $1 \%$ level; ++ $5 \%$ level; + $10 \%$ level. See other notes for Table 5. 


\section{Appendix Table A1 - Full Regression Output for Selected Dependent Variables}

\begin{tabular}{|c|c|c|c|}
\hline Control Variable & Insurance & Smoker & Excellent Health \\
\hline Treated*Post & $0.061(0.017)^{*}$ & $0.003(0.007)$ & $0.014(0.005)^{*}$ \\
\hline Age $=24$ & $-0.004(0.002)^{*}$ & $0.007(0.001)^{* *}$ & $-0.002(0.001)^{*}$ \\
\hline Age $=25$ & $-0.007(0.003)$ & $0.022(0.001)^{* *}$ & $-0.004(0.001)^{* *}$ \\
\hline Age $=27$ & $0.012(0.010)$ & $0.030(0.002)^{* *}$ & $-0.016(0.002)^{* *}$ \\
\hline Age $=28$ & $0.016(0.011)$ & $0.039(0.002)^{* *}$ & $-0.026(0.002)^{* *}$ \\
\hline Age $=29$ & $0.029(0.011)^{*}$ & $0.032(0.002)^{* *}$ & $-0.018(0.003)^{* *}$ \\
\hline Female & $0.070(0.006)^{* *}$ & $-0.056(0.005) * *$ & $-0.020(0.008)$ \\
\hline Non-Hispanic black & $-0.012(0.010)$ & $-0.126(0.009)^{* *}$ & $0.006(0.007)$ \\
\hline Hispanic & $-0.117(0.007)^{* *}$ & $-0.183(0.004) * *$ & $-0.019(0.005)^{* *}$ \\
\hline Other than black, Hispanic, or white & $-0.011(0.010)$ & $-0.025(0.013)$ & $-0.010(0.004)^{*}$ \\
\hline Currently married & $0.069(0.008)^{* *}$ & $-0.110(0.008) * *$ & $0.027(0.005)^{* *}$ \\
\hline High school degree but no further & $0.110(0.012)^{* *}$ & $-0.091(0.017)^{* *}$ & $0.039(0.009)^{* *}$ \\
\hline Some college but no 4-year degree & $0.171(0.017)^{* *}$ & $-0.161(0.014) * *$ & $0.051(0.008)^{* *}$ \\
\hline College graduate & $0.251(0.019)^{* *}$ & $-0.310(0.020)^{* *}$ & $0.111(0.009)^{* *}$ \\
\hline Between $\$ 10,000$ and $\$ 15,000$ & $-0.048(0.014)^{*}$ & $0.007(0.006)$ & $-0.008(0.018)$ \\
\hline Between $\$ 15,000$ and $\$ 20,000$ & $-0.070(0.018)^{*}$ & $0.021(0.011)$ & $-0.007(0.013)$ \\
\hline Between $\$ 20,000$ and $\$ 25,000$ & $-0.032(0.009)^{*}$ & $0.007(0.009)$ & $0.0001(0.009)$ \\
\hline Between $\$ 25,000$ and $\$ 35,000$ & $0.051(0.010)^{* *}$ & $-0.020(0.013)$ & $0.026(0.013)$ \\
\hline Between $\$ 35,000$ and $\$ 50,000$ & $0.120(0.009)^{* *}$ & $-0.036(0.014)$ & $0.044(0.010)^{* *}$ \\
\hline Between $\$ 50,000$ and $\$ 75,000$ & $0.169(0.011)^{* *}$ & $-0.063(0.016)^{* *}$ & $0.058(0.011)^{* *}$ \\
\hline$\$ 75,000$ and over & $0.179(0.012)^{* *}$ & $-0.057(0.015)^{*}$ & $0.108(0.012)^{* *}$ \\
\hline One child in household & $0.021(0.007)^{*}$ & $0.035(0.009)^{* *}$ & $-0.012(0.003)^{* *}$ \\
\hline Two children in household & $0.031(0.005)^{* *}$ & $0.044(0.012)^{*}$ & $-0.010(0.008)$ \\
\hline Three children in household & $0.020(0.008)$ & $0.055(0.010)^{* *}$ & $-0.025(0.011)$ \\
\hline Four children in household & $0.017(0.021)$ & $0.071(0.023)^{*}$ & $-0.038(0.016)$ \\
\hline Five or more children in household & $0.065(0.023)^{*}$ & $0.071(0.018)^{*}$ & $-0.007(0.012)$ \\
\hline Cell phone only & $-0.013(0.006)$ & $0.007(0.006)$ & $0.011(0.007)$ \\
\hline Student & $-0.006(0.016)$ & $-0.035(0.008)^{* *}$ & $0.013(0.009)$ \\
\hline Unemployed & $-0.164(0.017)^{* *}$ & $0.100(0.010)^{* *}$ & $-0.027(0.006)^{* *}$ \\
\hline State unemployment rate & $0.004(0.003)$ & $-0.009(0.004)^{*}$ & $0.002(0.002)$ \\
\hline Pre-ACA state mandate & $0.017(0.010)$ & $0.001(0.010)$ & $-0.015(0.004)^{*}$ \\
\hline
\end{tabular}

Notes: ** indicates significant at the $1 \%$ level; * $\%$ level. Standard errors, heteroskedasticity-robust and clustered by age, are in parentheses. All regressions also include the age, state, and time fixed effects. BRFSS sampling weights are used. Separate variables for "treated" and "post" are not included because they are subsumed by the age and time fixed effects. 